\title{
Global Patterns of Diapycnal Mixing from Measurements of the Turbulent Dissipation Rate
}

\author{
Amy F. Waterhouse, ${ }^{*}$ Jennifer A. MacKinnon, ${ }^{*}$ Jonathan D. Nash, ${ }^{+}$Matthew H. Alford, ${ }^{*}$ \\ Eric Kunze, ${ }^{\#}$ Harper L. Simmons, ${ }^{\circledR}$ Kurt L. Polzin, ${ }^{\&}$ Louis C. St. Laurent, ${ }^{\&}$ Oliver M. Sun, ${ }^{\&}$ \\ Robert Pinkel,* LynNe D. TAlley,* CAitlin B. Whalen,* TyCHO N. HuUsSen,* \\ GLENN S. CARTER, ** ILKER FER, ${ }^{++}$STEPHANIE WATERMAN,"\#,@@ \\ Alberto C. NAveira GARABATO, \&\& ThOmAs B. SANFOrD, ${ }^{\#}$ AND CrAig M. LEE ${ }^{\#}$ \\ * Scripps Institution of Oceanography, University of California, San Diego, La Jolla, California \\ ${ }^{+}$College of Oceanic and Atmospheric Sciences, Oregon State University, Corvallis, Oregon \\ \# Applied Physics Laboratory and School of Oceanography, University of Washington, Seattle, Washington \\ ${ }^{\circledR}$ University of Alaska Fairbanks, Fairbanks, Alaska \\ ${ }^{\&}$ Department of Physical Oceanography, Woods Hole Oceanographic Institution, Woods Hole, Massachusetts \\ ** Department of Oceanography, University of Hawai'i at Mānoa, Honolulu, Hawaii \\ ${ }^{++}$Geophysical Institute, University of Bergen, Bergen, Norway \\ \#\# Department of Earth, Ocean and Atmospheric Sciences, University of British Columbia, Vancouver, British Columbia \\ \&\& National Oceanography Centre, University of Southampton, Southampton, United Kingdom
}

(Manuscript received 15 May 2013, in final form 2 April 2014)

\begin{abstract}
The authors present inferences of diapycnal diffusivity from a compilation of over 5200 microstructure profiles. As microstructure observations are sparse, these are supplemented with indirect measurements of mixing obtained from (i) Thorpe-scale overturns from moored profilers, a finescale parameterization applied to (ii) shipboard observations of upper-ocean shear, (iii) strain as measured by profiling floats, and (iv) shear and strain from full-depth lowered acoustic Doppler current profilers (LADCP) and CTD profiles. Vertical profiles of the turbulent dissipation rate are bottom enhanced over rough topography and abrupt, isolated ridges. The geography of depth-integrated dissipation rate shows spatial variability related to internal wave generation, suggesting one direct energy pathway to turbulence. The global-averaged diapycnal diffusivity below 1000-m depth is $O\left(10^{-4}\right) \mathrm{m}^{2} \mathrm{~s}^{-1}$ and above $1000-\mathrm{m}$ depth is $O\left(10^{-5}\right) \mathrm{m}^{2} \mathrm{~s}^{-1}$. The compiled microstructure observations sample a wide range of internal wave power inputs and topographic roughness, providing a dataset with which to estimate a representative global-averaged dissipation rate and diffusivity. However, there is strong regional variability in the ratio between local internal wave generation and local dissipation. In some regions, the depthintegrated dissipation rate is comparable to the estimated power input into the local internal wave field. In a few cases, more internal wave power is dissipated than locally generated, suggesting remote internal wave sources. However, at most locations the total power lost through turbulent dissipation is less than the input into the local internal wave field. This suggests dissipation elsewhere, such as continental margins.
\end{abstract}

\footnotetext{
${ }^{\circledR @}$ Current affiliation: Climate Change Research Centre and ARC Centre of Excellence for Climate System Science, University of New South Wales, Sydney, Australia.
}

Corresponding author address: A. F. Waterhouse, Scripps Institution of Oceanography, University of California, San Diego, 9500 Gilman Drive, La Jolla, CA 92037.

E-mail: awaterhouse@ucsd.edu

\section{Introduction}

Understanding diapycnal mixing in the global ocean and how it is distributed is important, because diapycnal diffusivity plays a primary role in the meridional overturning and heat budget of the ocean (Munk and Wunsch 1998). Globally, 1-2 TW of diapycnal mixing is thought to be needed to maintain the observed stratification (Munk and Wunsch 1998; Wunsch and Ferrari 2004). 
The distribution of diapycnal mixing is extremely patchy in space, varying with both depth and location (Kunze et al. 2006; Whalen et al. 2012; MacKinnon et al. 2013b). Diapycnal mixing is often attributed to breaking internal waves. Mixing has been observed to be enhanced in regions of elevated internal wave generation, such as under storms (Dohan and Davis 2011) and near rough topography (Polzin et al. 1997). Some fraction of internal wave energy is lost due to wave breaking locally near generation sites (Large and Crawford 1995; Klymak et al. 2008; Alford et al. 2012). Internal waves that are not dissipated locally propagate away, losing energy to processes such as topographic scattering and reflection (Müller and Xu 1992) and nonlinear transfer to smaller-scale waves that ultimately break (Polzin 2004b; MacKinnon et al. 2013a). Some of this energy is channeled through the broadband internal wave field (Polzin 2004a). Internal waves that do not lose power as they propagate across the ocean basins may dissipate when they crash onto continental margins (Nash et al. 2004, 2007; Zhao and Alford 2009; Legg 2014). A better understanding of the relative proportion of internal wave energy that dissipates locally (within a mode- 1 internal wavelength) versus remotely is required to predict the global geography of diapycnal mixing.

Diapycnal mixing in the deep ocean plays an important role in the global meridional overturning circulation, as downward buoyancy fluxes lighten both deep and bottom waters. Global and basin-specific calculations suggest that an average diapycnal diffusivity $O\left(10^{-4}\right) \mathrm{m}^{2} \mathrm{~s}^{-1}$ is required in the abyssal ocean to explain observed water mass transformation rates (Munk 1966; Munk and Wunsch 1998; Lumpkin and Speer 2007; Macdonald et al. 2009), while $O\left(10^{-5}\right) \mathrm{m}^{2} \mathrm{~s}^{-1}$ is required in the main thermocline (Lumpkin and Speer 2007). These values are roughly consistent with a variety of inverse models summarized in Wunsch and Ferrari (2004), and the meridional overturning circulation as a whole (Talley 2013). Below, we demonstrate that existing observations, though sparse and variable, are on average consistent with the required predicted diffusivity.

The supply of internal wave energy into the ocean comes primarily from two sources: winds acting on the mixed layer generating near-inertial waves below (0.3-1.5 TW; Lueck and Reid 1984; D'Asaro 1985, 1995; Large and Crawford 1995; Watanabe and Hibiya 2002; Alford 2003; Jiang et al. 2005; Plueddemann and Farrar 2006; Furuichi et al. 2008; Rimac et al. 2013) and tidal flows over topography (0.7-1.3 TW; Munk 1966; Baines 1982; Sjöberg and Stigebrandt 1992; Munk and Wunsch 1998; Egbert and Ray 2000; Nycander 2005; Garrett and Kunze 2007). Mesoscale flow over rough topography generates internal lee waves (Nikurashin and Ferrari 2011; Melet et al. 2014), but we will not include lee-wave generation as it remains less well understood, under observed, and a weaker power source (0.2 TW; Nikurashin and Ferrari 2011).

In this work, we have compiled a set of turbulent mixing data, with measurements taken in diverse oceanic regimes, including midocean ridges, isolated abrupt ridges, and the quiet ocean interior. The goals of this work are to (i) quantify bulk statistical properties of the complete dataset, including average deep-ocean diffusivity, and (ii) investigate whether the distribution of the observed mixing rate can, in conjunction with our understanding of the geography of internal wave generation and propagation, yield insight into the distribution of internal wave dissipation and the relation between internal wave generation and dissipation.

We first discuss the patterns of diapycnal mixing, and then relate global power sources for internal waves to these observations. We then investigate how the observations fit between several conceptually idealized hypotheses. At one extreme, all of the power input to the internal wave field could be dissipated locally, resulting in a global map of depth-integrated dissipation that is identical to the global map of internal wave generation. In a second scenario, a fraction of power input is dissipated locally, and the rest dissipates in the ocean interior as low-mode waves propagate through ocean basins. The final scenario is that low-mode wave energy propagates freely across entire ocean basins to dissipate only where waves encounter continental slopes and shelves. We will show that the observations vary regionally between these scenarios, depending on the character of local power input and topography.

\section{Data}

Direct measurements of the turbulent kinetic energy dissipation rate $\epsilon$ have been made by a number of groups deploying microstructure profilers that measure microscale shear (Table 1). St. Laurent and Simmons (2006) compiled microstructure observations with a similar goal of calculating global-averaged diffusivities. Here, we add the datasets from the Pacific Equatorial Ocean Dynamics (PEQUOD), FLUX91, Coupled OceanAtmosphere Response Experiment (COARE), Faroe Bank Channel, GRAVILUCK, Larval Dispersal on the Deep East Pacific Rise (LADDER), Tongue of the Ocean (TOTO), Southern Ocean Fine structure (SOFine), Weddell Sea, Diapycnal and Isopycnal Mixing Experiment in the Southern Ocean (DIMES), Experiment on Internal Tidal Scattering (EXITS), Samoan Passage Abyssal Mixing (SPAM), Mixing in the Equatorial Thermocline (MIXET), and GEOTRACES (Table 1). For experiments that are known to span different 
regimes, data were subdivided. For example, Brazil Basin Tracer Release Experiment (BBTRE) data were divided into smooth (west of $28^{\circ} \mathrm{W}$ ) versus rough topography (east of $28^{\circ} \mathrm{W}$ ). GEOTRACES profiles from along $40^{\circ} \mathrm{S}$ in the Argentine Basin were divided between those over the Mid-Atlantic Ridge and west of $19^{\circ} \mathrm{W}$. EXITS data were subdivided between over the steep Line Islands chain and the nearby abyssal region. Observations from overflow regions [GRAVILUCK, below 2000-m depth; SPAM (G. S. Carter 2013, unpublished data); Faroe Bank Channel, Fer et al. (2010); Weddell Sea (I. Fer 2013, unpublished data)] are included in our qualitative description of global mixing patterns but not considered in the calculation of global-averaged diffusivities and the more quantitative discussion of sections $3 \mathrm{c}-\mathrm{e}$, because overflows differ from the internal wave generation and breaking that are the focus here.

Other historical observations of diapycnal diffusivity, compiled in Gregg (1998), have been procured from published literature (Osborn 1978, 1980; Lueck et al. 1983; Lueck and Osborn 1985, 1986; Gregg et al. 1986; Lueck 1988; Gregg 1989; Wesson and Gregg 1994; Polzin et al. 1996). Average diffusivities from these historical measurements, while consistent with more recent observations, are presented for reference only (Fig. 1) and are not used in subsequent calculations as vertical profiles are no longer available. Observations from the Arctic Ocean, which has a different internal wave regime (Levine et al. 1987; D'Asaro and Morehead 1991; Wijesekera et al. 1993; Pinkel 2005) and occupies a small volume of the World Ocean, are not considered.

The dissipation rate in an isotropic turbulence field can be expressed as

$$
\epsilon=7.5 \nu \overline{\left(\frac{\partial u}{\partial z}\right)^{2}} \quad\left(\mathrm{~m}^{2} \mathrm{~s}^{-3}\right)
$$

where $\nu$ is the viscosity of water, and $\partial u / \partial z$ is the velocity shear resolved to dissipative scales $\left(\nu^{3} / \epsilon\right)^{1 / 4}$ (Thorpe 2007). Velocity shear is measured with free-falling microstructure profilers (Osborn and Crawford 1980; Lueck et al. 1997; Gregg 1999) or towed bodies (Moum et al. 2002) with airfoil probes that measure highfrequency velocity fluctuations. As small-scale velocity gradients are not fully resolved by most instruments, spectral estimates of spatial gradients of velocity are fit to a known universal model spectrum (Nasmyth 1970), which is then integrated to calculate $\epsilon$ (Oakey 1982; Wesson and Gregg 1994). Diffusivity $K$ is related to the dissipation rate through a dissipation flux coefficient $\Gamma$

$$
K=\Gamma \epsilon \overline{N^{2}} \quad\left(\mathrm{~m}^{2} \mathrm{~s}^{-1}\right),
$$

(Moum 1996a) where $\bar{N}$ is the depth-averaged buoyancy frequency and $\Gamma$ is taken to be 0.2 (Osborn 1980), although known to vary (St. Laurent and Schmitt 1999). Only microstructure observations below the mixed-layer depth (MLD) are included. The MLD is identified using a cutoff at a density difference of $0.03 \mathrm{~kg} \mathrm{~m}^{-3}$ or a temperature difference of $0.2^{\circ} \mathrm{C}$ from its value at $10 \mathrm{dbar}$ (Holte and Talley 2009). Stratification $N$ is calculated for each profile using the method of adiabatic leveling (Bray and Fofonoff 1981). Average profiles of turbulent dissipation rate and diffusivity are binned into $150-\mathrm{m}$ intervals.

Moored profilers provide near-full water column profiles of density from which the dissipation rate can be calculated from density overturns (Thorpe 1977; Dillon 1982; Crawford 1986; Ferron et al. 1998; Alford et al. 2006; Alford 2010). These profilers have been deployed (Fig. 1a) near Mendocino Escarpment, Monterey Submarine Canyon, Oregon slope, Hawaii [Internal Waves Across the Pacific (IWAP); Hawaii Ocean Mixing Experiment (HOME)], Taiwan [Internal Waves in Straits Experiment (IWISE)], Philippines [Philippines Strait Dynamics Experiment (PHILEX)], and the South China Sea.

Other indirect estimates of diffusivity are derived from application of a finescale parameterization to measurements of shear and strain (Gregg 1989; Gregg and Kunze 1991; Polzin et al. 1995; Gregg et al. 2003). Many of the diffusivity inferences in Figs. 1a and $1 \mathrm{~b}$ are from previously published work in which diffusivity was inferred from lowered acoustic Doppler current profilers (LADCP) and CTD profiles (Kunze et al. 2006; Huussen et al. 2012).

To these observations, we add unpublished estimates of finescale-inferred diffusivity using velocity observations from the 50-kHz Hydrographic Doppler Sonar System (HDSS) aboard the Research Vessel (R/V) Revelle during 2008-12 to 1000-m depth. Using the finescale parameterization, diffusivity from shipboard sonar can be inferred (MacKinnon et al. 2013a) by relating the variance of the buoyancy frequency-normalized shear $\left\langle V_{z}^{2}\right\rangle / \overline{N^{2}}$ normalized by the Garrett-Munk (GM) spectra shear variance (Gregg et al. 2003), where angle brackets denote integration over internal wave scales. Buoyancy frequency from the World Ocean Circulation Experiment (WOCE) Global Hydrographic Climatology (Gouretski and Koltermann 2004) is used to normalize the observed shear spectrum. The spectrum of cross-ship shear from the shipboard sonar (Pinkel 2012) is integrated up to $0.01 \mathrm{cpm}^{-1}$, and the diffusivity is calculated as

$$
K=K_{0} \frac{\overline{N^{2}}}{N_{0}^{2}} \frac{\left\langle V_{z}^{2}\right\rangle^{2}}{\mathrm{GM}^{\langle}\left\langle V_{z}^{2}\right\rangle^{2}} h\left(R_{\omega}\right) L\left(\frac{f}{N}\right) \quad\left(\mathrm{m}^{2} \mathrm{~s}^{-1}\right)
$$

(Gregg et al. 2003), where $K_{0}=0.05 \times 10^{-4} \mathrm{~m}^{2} \mathrm{~s}^{-1}, N_{0}=$ $5.24 \times 10^{3} \mathrm{rad} \mathrm{s}^{-1}, \mathrm{GM}\left(\left\langle V_{z}^{2}\right\rangle / N_{0}^{2}\right)$ is the normalized shear 
variance from the GM model spectrum (Munk 1981; Gregg and Kunze 1991), $h\left(R_{\omega}\right)$ is a function related to the shear-to-strain variance ratio, $f$ is the Coriolis frequency, and $L(f / N)$ is a function expressing the latitudinal dependence. In this case, a constant $R_{\omega}=7$ (Kunze et al. 2006) is used.

Strain-based upper-ocean diffusivities spanning 2502000-m depth are inferred from over 200000 Argo float profiles, also through the finescale parameterization using $R_{\omega}=3$ (Whalen et al. 2012). The function analogous to $h$ $\left(R_{\omega}\right)$ will be a factor of 2 smaller than those for $R_{\omega}=7 \mathrm{used}$ here (Kunze et al. 2006) and are only presented in Fig. 1a as a comparison to the microstructure observations.

\section{Global patterns and averages of diffusivity and power input}

\section{a. Diapycnal diffusivity: Global patterns}

In general, the compiled data (Fig. 1) show elevated diffusivities associated with more complex topography, consistent with patterns presented by Decloedt and Luther (2010) and Whalen et al. (2012). Inferred estimates from HDSS shear show elevated diffusivities in the upper $1000 \mathrm{~m}$ of the water column on the western side of the Indian Ocean, particularly over the Southwest Indian Ridge, with levels in agreement with Kunze et al. (2006) (Fig. 1a). The eastern portion of the Indian Ocean has lower diffusivity $\left(K \sim 10^{-6} \mathrm{~m}^{2} \mathrm{~s}^{-1}\right)$. A transect from South Africa to the United States shows elevated diffusivities over the Mid-Atlantic Ridge, decreasing away from topography as found by Polzin et al. (1997) in the Brazil Basin. As previously documented with other observations, the South China Sea (Alford et al. 2011) and Hawaiian Ridge (Klymak et al. 2006) both have diffusivities as high as $K \sim 10^{-3} \mathrm{~m}^{2} \mathrm{~s}^{-1}$. Elevated diffusivities are also found south of Australia and in the Southern Ocean east of South America (Heywood et al. 2002).

Equatorial regions also show enhanced diffusivity, which has been linked to diurnal deep-cycle turbulence, tropical instability waves, and instabilities of the Equatorial Undercurrent (Moum et al. 2009), processes that are likely confined to the upper ocean. Finescale diffusivity parameterizations based on internal wave dynamics may not be appropriate in such situations, but are presented for comparison with direct microstructure measurements (Figs. 1, 3, 6; note that Figs. 3 and 6 are described in greater detail below). Areas of enhanced diffusivities have also been linked to increased eddy kinetic energy (Whalen et al. 2012), but this is not considered here because the magnitude and processes through which eddy kinetic energy is made available to small-scale turbulence are unclear.

\section{b. Diapycnal diffusivity: Global averages}

Depth-averaged diffusivities are calculated over three depth ranges (from MLD to 1000-m depth, from MLD to the bottom, and from 1000-m depth to the bottom) from the project-averaged microstructure diffusivity profiles. These depth ranges are chosen to cover (i) the upper ocean (where the majority of microstructure profiles have been collected) and (ii) below 1000-m depth, where inverse bulk budgets suggest the average diffusivity is enhanced (Lumpkin and Speer 2007). Each project-averaged profile was given equal weight in the calculation of global averages. Overflow observations [GRAVILUCK (below $2000 \mathrm{~m}$ ), SPAM, Faroe Bank and Weddell Sea] were not included. Specific projects used to calculate depth-averaged diffusivities within the particular depth ranges are listed in Table 2. Average diffusivities presented here are based only on microstructure data as these proved the most accurate estimates of the small scales at which turbulent dissipation occurs. Global estimates of diffusivity based on the finescale parameterization are presented in Kunze et al. (2006) and Whalen et al. (2012).

Average (upper and lower $95 \%$ bootstrap confidence limits) diffusivities are $0.3(0.2-0.4) \times 10^{-4} \mathrm{~m}^{2} \mathrm{~s}^{-1}$ for the upper 1000-m from 21 project-averaged profiles. Average diffusivity $K$ for the full water column (from MLD to bottom) is an order of magnitude larger at $3.3(0.2-8.6) \times$ $10^{-4} \mathrm{~m}^{2} \mathrm{~s}^{-1}$ from 17 project-averaged profiles, while the average abyssal $K$ (below 1000 -m depth) is $4.3(0.4-11.5) \times$ $10^{-4} \mathrm{~m}^{2} \mathrm{~s}^{-1}$ from 17 project-averaged profiles.

\section{c. Total global power input}

Patterns of turbulent dissipation are compared to internal wave generation from winds and tides because internal wave breaking is thought to be responsible for most turbulent dissipation in the ocean interior. These two sources of power have distinct global patterns (Figs. 2a,b). Estimates of tidal conversion and wind generation are calculated from simulations using an isopycnal, eddyresolving, global internal wave Generalized Ocean Layer Dynamics model (GOLD; http://www.gfdl.noaa.gov/ ocean-model) on a $1 / 8^{\circ}$ Mercator projection, such that the resolution is $1 / 8^{\circ} \times 1 / 8^{\circ}$ at the equator (approximately $14 \mathrm{~km} \times 14 \mathrm{~km}$ ), telescoping to $7 \mathrm{~km} \times 7 \mathrm{~km}$ at $60^{\circ}$ latitude. The 3-hourly and $0.5^{\circ}$-resolution Navy Operational Global Atmospheric Prediction System (NOGAPS; Hogan and Rosmond 1991; Rosmond 1992; e.g., Simmons et al. 2004b) winds are used (Simmons and Alford 2012).

The tide has long been argued to be the strongest power source for internal waves (Munk and Wunsch 1998; MacKinnon et al. 2013b). Conversion from barotropic to baroclinic tide is based on a decomposition of 


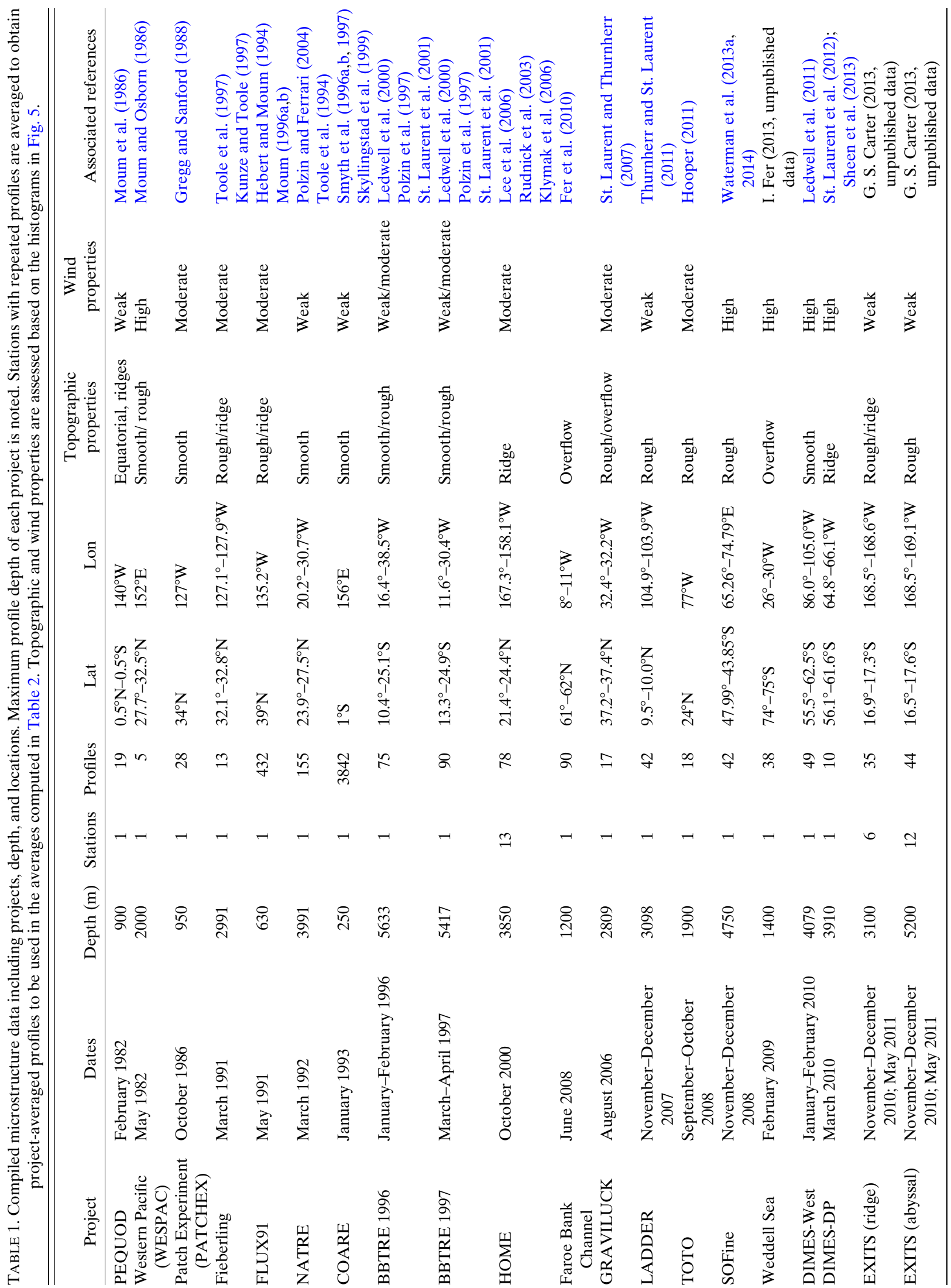




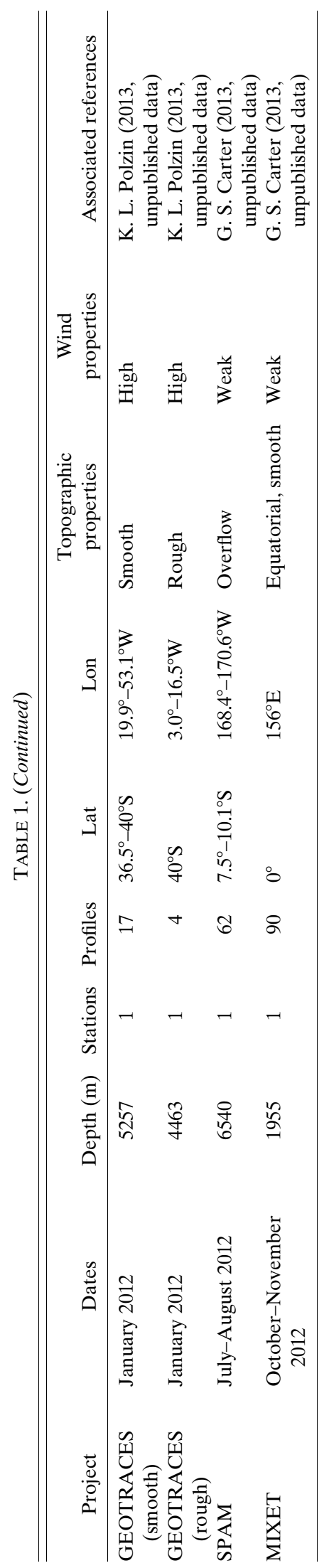

the barotropic and baroclinic energy equations (Simmons et al. 2004a). This calculation only accounts for linear conversion and slightly underestimates it due to inadequate resolution of bottom roughness (Simmons et al. 2004a), but produces results similar to other similarly hampered conversion estimates (Kurapov et al. 2003; Kelly et al. 2010). The average semidiurnal tidal conversion (during January; limited to 1 month due to computational constraints) shows the expected elevated levels along midocean ridges and topographic features (Fig. 2a). Globally, barotropic to baroclinic tidal conversion between $60^{\circ} \mathrm{N}$ and $60^{\circ} \mathrm{S}$ is 1.5 $\mathrm{TW}$, where $1.1 \mathrm{TW}$ of the total conversion is below $500-\mathrm{m}$ depth. While this power input has a factor of 2 uncertainty associated with its calculation, this estimate is within a factor of 2 of the 0.7-1.3-TW range of previous semidiurnal tide estimates (Sjöberg and Stigebrandt 1992; Munk and Wunsch 1998; Egbert and Ray 2001; Nycander 2005).

The character and strength of internal tide generation can be subdivided into three different topographic regimes, depending on depth, bottom slope, and internal wave ray slope (St. Laurent and Garrett 2002; St. Laurent et al. 2003; Garrett and Kunze 2007). These define 1) smooth topography; 2) abrupt, isolated ridges $[h / H \sim 1$, where $h$ is the topographic height and $H$ the water depth, and $s / \alpha \geq 1$ with $s$ as the bottom slope and $\alpha$ as the internal wave ray slope (St. Laurent et al. 2003)]; and 3) rough topography with smaller ridges $(h / H \ll 1)$ and abyssal hills $[s / \alpha \ll 1$ as treated by Bell (1975)]. An analysis of mixing rates corresponding to each of these topographic regimes is presented in subsequent sections.

The majority of the total global wind power input ( $\sim 60$ TW; Wang and Huang 2004) generates surface waves and mixed layer turbulence. Between 0.3 and 1.5 TW goes into mixed layer inertial oscillations (Alford 2001; Watanabe and Hibiya 2002; Alford 2003; Jiang et al. 2005; Furuichi et al. 2008; Rimac et al. 2013). The range is large because of the sensitivity of the calculation to the wind product used (Jiang et al. 2005). Many of these estimates come from treating the mixed layer as a uniform slab (D'Asaro 1985). Plueddemann and Farrar (2006) have pointed out that slab models may overestimate true near-inertial wind work because they do not account for dissipation and mixing at the mixed layer base at the onset of near-inertial events. Because direct estimates are rare, only a handful of comparisons have been made, with the ratio of slab model wind work to the total ranging from no bias (Alford et al. 2012) to 2-4 (Plueddemann and Farrar 2006). Of the total input to mixed layer inertial motions, an uncertain fraction radiates away as low-mode near-inertial waves (Large and Crawford 1995; Alford 2003; Alford et al. 2012). The remainder dissipates locally through shear instability or relatively local breaking of high-mode near-inertial 


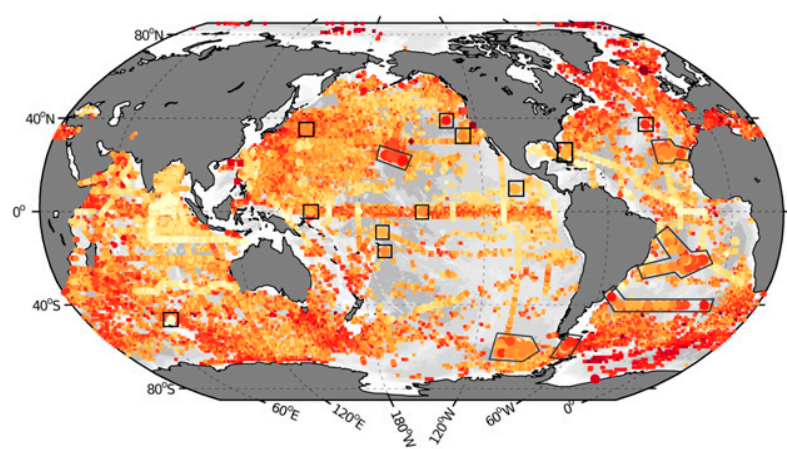

(a) Upper $1000 \mathrm{~m} \log _{10} K$

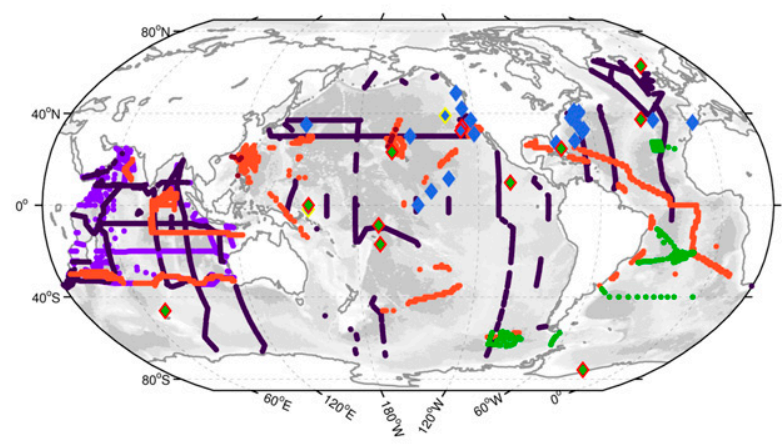

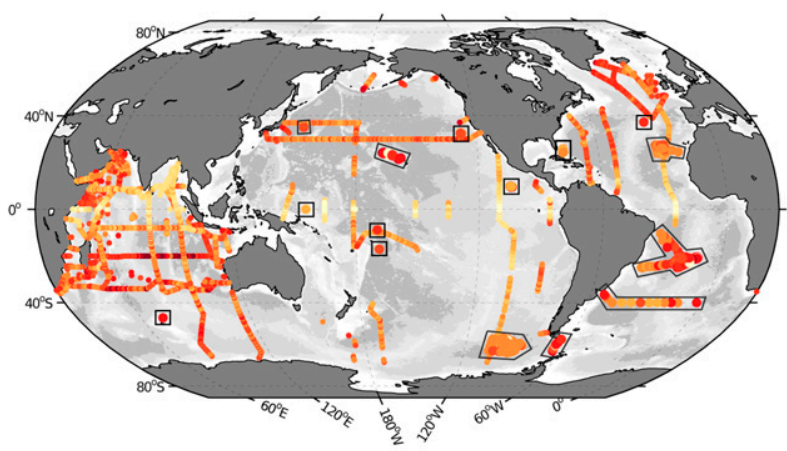

(b) Full depth $\log _{10} K$

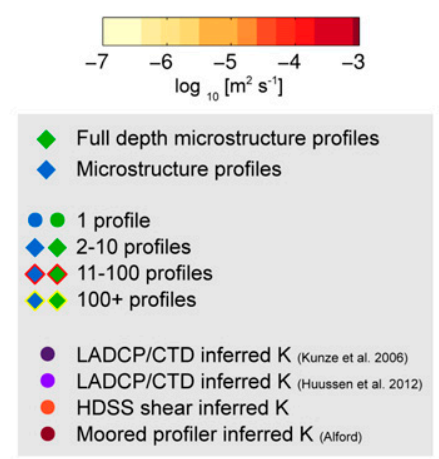

(c) Observations of mixing

FIG. 1. Depth-averaged diffusivity $K$ from (a) the upper ocean (from MLD to 1000-m depth) and (b) the full water column. The background diffusivity map in (a) comes from the strain-based inferences of diffusivity from Argo floats (Whalen et al. 2012). (c) Compiled observations of mixing measurements with blue and green squares and diamonds denoting microstructure measurements. Green represents full-depth profiles, while blue denotes microstructure profiles. Purple circles represent inferred diffusivity from a finescale parameterization using LADCP/CTD profiles [dark purple, Kunze et al. (2006); medium purple, Huussen et al. (2012)] and HDSS shipboard shear (light orange). Dark orange circles are diffusivities from density overturns in moored profiles.

waves. Here, power input from the winds is computed as $\tau \cdot \mathbf{u}$, where $\tau$ is the wind stress from NOGAPS winds and $\mathbf{u}$ is the high-pass-filtered sea surface velocity from the GOLD simulation (Simmons and Alford 2012). Wind power input is strongest near midlatitude storm tracks (Fig. 2b). In the model used here, the total global power input from the winds to near-inertial low modes is $0.3 \mathrm{TW}$ between $60^{\circ} \mathrm{N}$ and $60^{\circ} \mathrm{S}$ (with a factor of 2 uncertainty associated with this calculation) at the lower end of previous estimates.

Though the estimated total magnitude of power input from both wind- and tide-generated internal waves has considerable range in the literature, the patterns for both are fairly consistent between different estimates. These patterns will be compared with the observed distribution of turbulent dissipation below. The sum of the expected source terms (winds and tides; Fig. 2c) is used to investigate how the spatial patterns of internal wave energy sources relate to the spatial variability of mixing observed.

\section{d. Comparison of power input to observed integrated dissipation rates}

In a steady ocean, energy conversion describing the total internal wave dissipation $D(\mathbf{x})$ is

$$
D(\mathbf{x})=S(\mathbf{x})-\nabla \cdot F(\mathbf{x}),
$$

where $S(\mathbf{x})$ is the internal wave generation source term (from winds and tides), and $\boldsymbol{\nabla} \cdot F(\mathbf{x})$ is the internal wave energy-flux divergence (Müller and Olbers 1975; Polzin 2004a).

The total dissipation rate in the water column $D(\mathbf{x})$ includes both the depth-integrated turbulent kinetic energy dissipation rate $\epsilon_{\text {total }}$ and buoyancy flux $J_{B}$ :

$$
\begin{aligned}
D(\mathbf{x}) & =\epsilon_{\text {total }}+J_{B}, \\
& =\frac{\epsilon}{(1-\Gamma)} .
\end{aligned}
$$


TABLE 2. Average diffusivity $K\left(\mathrm{~m}^{2} \mathrm{~s}^{-1}\right)$ from the upper-ocean (from the MLD to 1000-m depth), full-depth microstructure profiles (from MLD to the bottom) and deeper ocean (from 1000-m depth to the bottom). Diffusivities in the parentheses are the upper and lower bounds of the $95 \%$ bootstrap confidence intervals. Projects included in the averages are listed and described in Table 1 .

\begin{tabular}{|c|c|c|c|}
\hline & Depth range & $K\left(\mathrm{~m}^{2} \mathrm{~s}^{-1}\right)$ & Projects included in average \\
\hline Full depth & From MLD to bottom & $3.3(0.2-8.6) \times 10^{-4}$ & $\begin{array}{l}\text { WESPAC, GEOTRACES (smooth and rough), } \\
\text { Fieberling, NATRE, BBTRE (smooth and rough), } \\
\text { HOME, GRAVILUCK (above } 2000 \mathrm{~m} \text { ), LADDER, } \\
\text { TOTO, SOFine, DIMES (DP and West), EXITS (ridge } \\
\text { and abyssal), and MIXET }\end{array}$ \\
\hline Upper ocean & From MLD to $1000-m$ depth & $0.3(0.2-0.4) \times 10^{-4}$ & $\begin{array}{l}\text { PEQUOD, PATCHEX, FLUX91, COARE, WESPAC, } \\
\text { GEOTRACES (smooth and rough), Fieberling, NATRE, } \\
\text { BBTRE (smooth and rough), HOME, GRAVILUCK } \\
\text { (above } 2000 \mathrm{~m} \text { ), LADDER, TOTO, SOFine, DIMES } \\
\text { (DP and West), } \\
\text { EXITS (ridge and abyssal), and MIXET }\end{array}$ \\
\hline Deeper ocean & From $1000-\mathrm{m}$ depth to bottom & $4.3(0.4-11.5) \times 10^{-4}$ & $\begin{array}{l}\text { WESPAC, GEOTRACES (smooth and rough), Fieberling, } \\
\text { NATRE, BBTRE (smooth and rough), HOME, } \\
\text { GRAVILUCK (above } 2000 \mathrm{~m} \text { ), LADDER, TOTO, SOFine, } \\
\text { DIMES (DP and West), EXITS (ridge and abyssal), } \\
\text { and MIXET }\end{array}$ \\
\hline
\end{tabular}

Variable $\epsilon$ is the observed depth-integrated turbulent dissipation rate and $(1-\Gamma)$ is the energy presumed lost to irreversible mixing (Munk and Wunsch 1998; Wunsch and Ferrari 2004). Here, we take $\Gamma=0.2$ (Osborn 1980).
The average total dissipation $D$ is compared to the average power input from wind and tides in $1^{\circ} \times 1^{\circ}$ squares centered around the location of the microstructure observations (Fig. 3). Errors associated with either

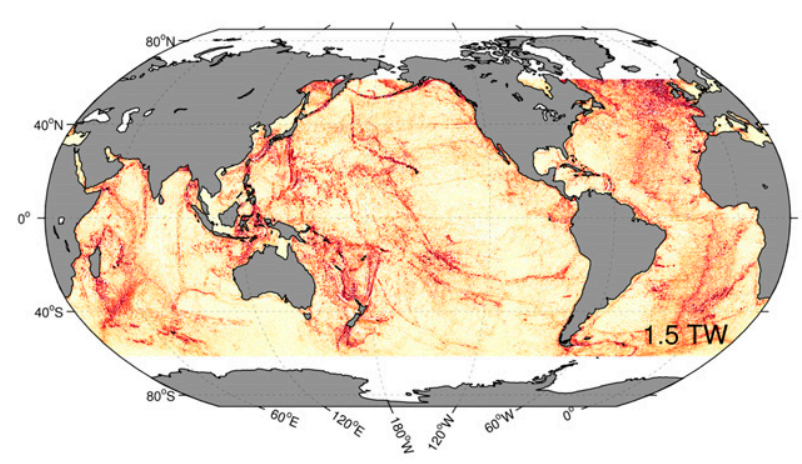

(a) Internal tides

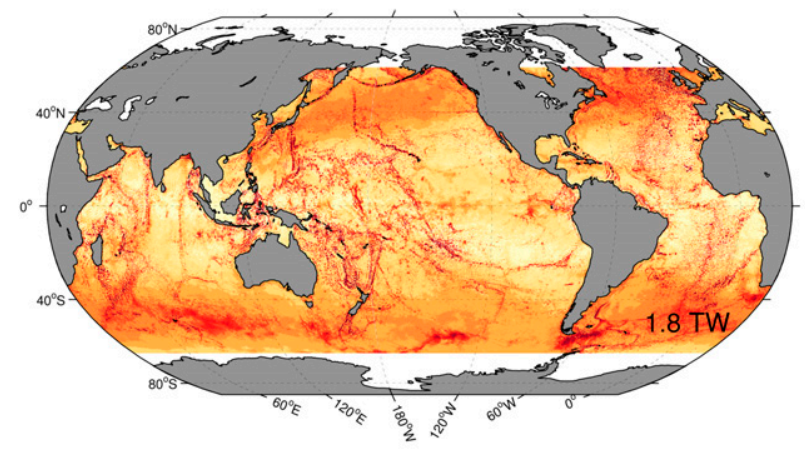

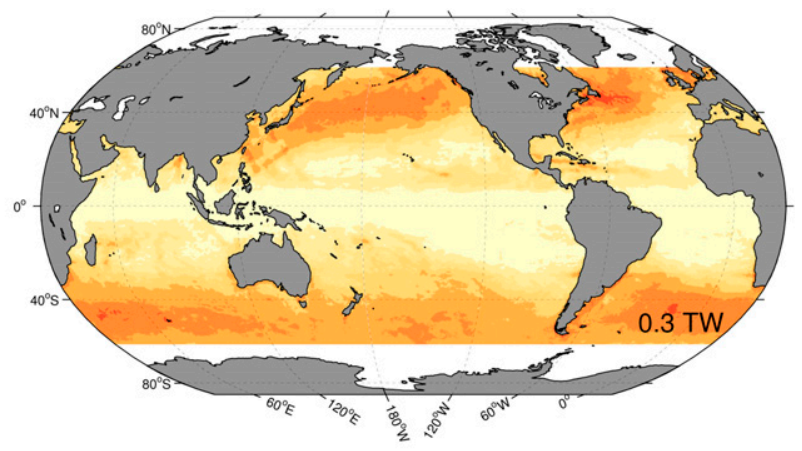

(b) Near-inertial waves

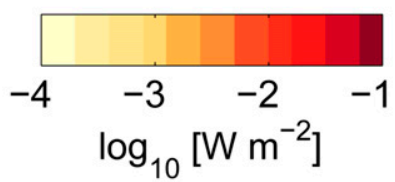

(c) Total source terms

FIG. 2. Source terms for the power input to the oceanic internal wave field plotted as $\log _{10}\left(\mathrm{~W} \mathrm{~m}^{-2}\right)$. The combined source terms from the (a) tides and (b) winds give (c) the total source map. Total power (TW) is noted in the bottom-right corner of each source map. Other sources, for example, geostrophic flow conversion to lee waves (Nikurashin and Ferrari 2011), are not considered here. 

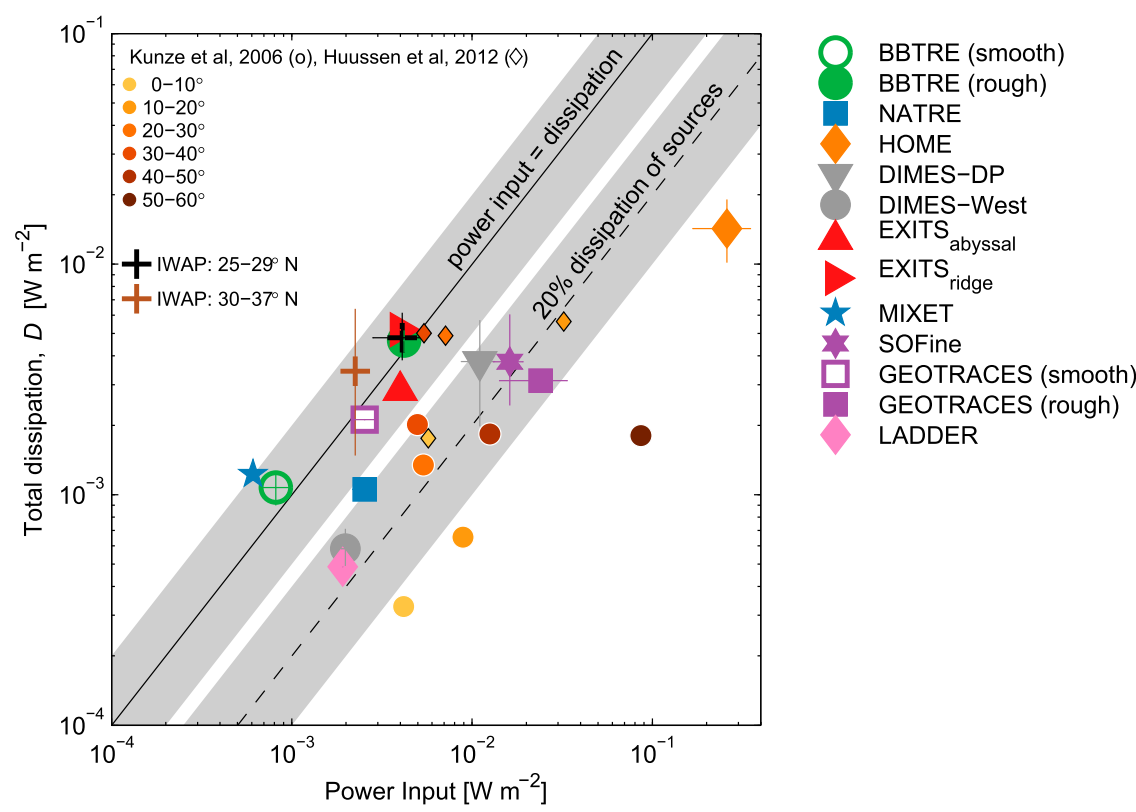

FIG. 3. Total power input $\left(\mathrm{W} \mathrm{m}^{-2}\right)$ from Fig. 2c compared to project-averaged observed total dissipation $D\left(\mathrm{~W} \mathrm{~m}^{-2}\right)$ from both microstructure measurements (right-hand legend) and the finescale inferences (Kunze et al. 2006; Huussen et al. 2012; orange diamonds and circles). BBTRE and GEOTRACES data are grouped by profiles collected over smooth and rough topography. Black diagonals represent $100 \%$ (1.8 TW, $1: 1$ ratio; solid) and $20 \%(0.36 \mathrm{TW}, 20 \%$ dissipation of total power input; dashed) of the total power input. Gray shaded regions represent the factor of 2 uncertainty associated with the estimated power input. Note that IWAP observations are calculated using a finescale parameterization applied to shear and strain from six moored profilers over 80- and 1000-m depth (MacKinnon et al. 2013a), extrapolated to the bottom using profiles of buoyancy frequency from WOCE Global Hydrographic Climatology. Error bars on microstructure observations are based on $95 \%$ bootstrapped confidence intervals for both the observed $D$ and power input. Datasets with only a single average profile have no associated bootstrapped error bars (MIXET and EXITS).

tidal or wind power inputs, or observed dissipations, are about a factor of 2 . For points falling on the $1: 1$ ratio line in Fig. 3, an equal amount of power is converted into internal waves as turbulently dissipated, suggesting possible local balance. Essentially, $D(\mathbf{x}) \approx S(\mathbf{x})[(4)]$, though energy influx from neighboring regions can also contribute to local dissipation. Below the 1:1 ratio line, sources of power input to the internal wave field exceeds local dissipation, suggesting a divergent energy flux $F(x)$ as waves propagate away. The ratio between the power dissipated to power input $q_{\text {ratio }}$ represents an upper bound on the amount of local dissipation at a given location and may be greater than 1 in regions where remotely incident sources are dissipated within the observation region. The conclusions reached here are relatively insensitive to the averaging box for $0.5^{\circ} \times 0.5^{\circ}$ to $4^{\circ} \times 4^{\circ}$.

The points in Fig. 3 are mostly on or below the 1:1 ratio line, representing a wide range of dynamical scenarios. The percentage of energy dissipated locally versus remotely is expected to vary considerably among datasets. In some places, such as over the rough topography of the eastern Brazil Basin [BBTRE (rough)], a local balance between generation and dissipation is suggested (Polzin 2004b; O. M. Sun et al. 2014, unpublished manuscript). Consistent with this interpretation, the BBTRE (rough) point in Fig. 3 falls on the 1:1 ratio line. In other places [e.g. EXITS (ridge)], waves generated at tall, steep topography may radiate away, but other waves that are incident from elsewhere (the Hawaiian Ridge, in this case) break on this ridge (Johnston et al. 2003), resulting in a point also appearing on the 1:1 line, but not because of a local balance.

Observations lying along or slightly above the ratio representing $20 \%$ local dissipation of power input [DIMES-West, DIMES-Drake Passage (DP), SOFine, GEOTRACES (rough), and LADDER] indicate that most of the internal wave energy generated at these sites escapes to dissipate elsewhere. Previous work by Klymak et al. (2006) estimated that less than $20 \%$ of the internal tide generated at the Hawaiian Ridge (HOME) is dissipated locally. Finescale parameterization-integrated dissipation rates (Kunze et al. 2006; Huussen et al. 2012) 

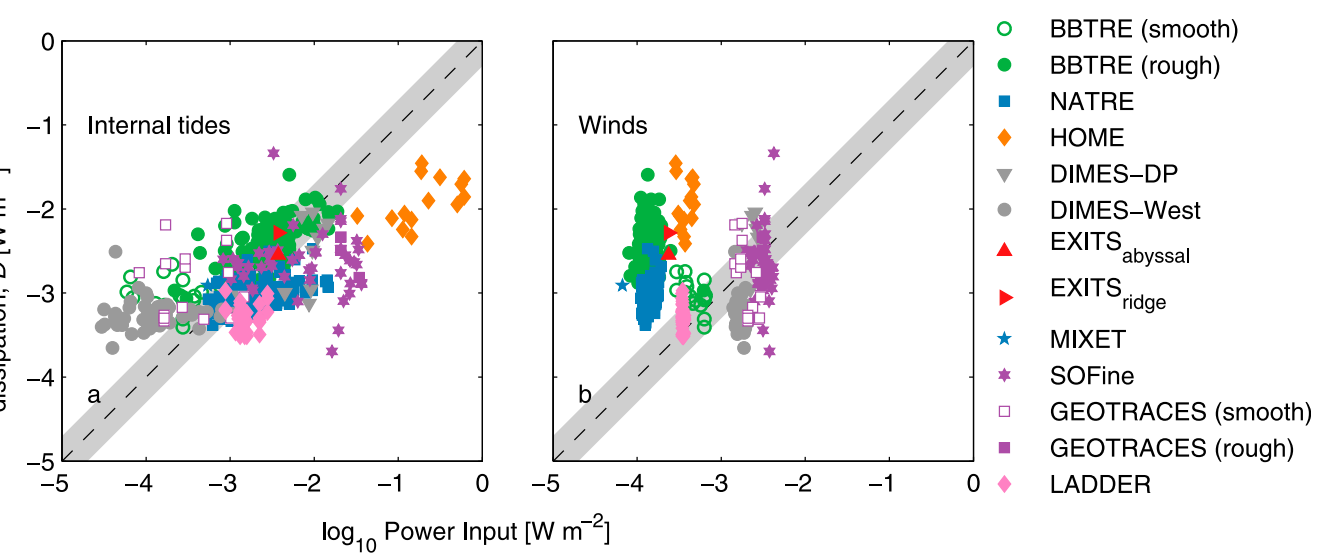

FIG. 4. Relationship between observed total dissipation $D$ and (a) internal tide and (b) wind power. Individual profiles are plotted except for MIXET and EXITS, where the project-averaged depth-integrated dissipation is plotted. Black dashed lines in each figure represent the 1:1 ratio, indicative of regions where the power into the internal wave field is equal to the amount dissipated. Gray shaded regions represent the factor of 2 uncertainty associated with the estimated power input.

are also included in Fig. 3, separated by the latitudinal band. They fall below the 1:1 ratio line, consistent with microstructure observations.

All but one set of microstructure observations (HOME) are above the ratio corresponding to $20 \%$ of the power input to internal waves, suggesting that, away from abrupt ridges that are efficient generators of lowmode internal waves, at most $20 \%$ of the local energy input may be locally dissipated (St. Laurent and Nash 2004).

In general, most observations of depth-integrated dissipation fall below the 1:1 ratio line, suggesting that a portion of the power input to the internal wave field is lost to radiation at most sites. Consider the three hypotheses laid out at the end of section 1 . The first scenario, where all of the local power input is dissipated locally, would manifest as points on the 1:1 line, which is observed in some locations but not globally. The second scenario, where radiated power is dissipated in the basin interior, would suggest that an equal number of points would be found above and below the 1:1 line. In other words, we would expect to see some locations where internal waves were generated but not entirely dissipated (e.g., the Hawaiian Ridge), but other locations where there was not strong local generation but dissipation of low-mode waves arriving from elsewhere. IWAP and EXITS datasets are both examples of this situation. However, overall there is not an equal distribution of points above and below the 1:1 ratio line, but more points below the line. This suggests that the third scenario may be the most common where some percentage of the generated energy is not dissipating in the ocean basin interior, but at basin margins. Quantitatively, an average of the points presented in Fig. 3 suggests $69 \%$ of the power input is dissipated in the basin interior. Uncertainties and implications will be discussed further in section 4 .

\section{e. Comparison of individual sources to observed integrated dissipation rates}

In this section, internal tide and wind power sources are separately compared to the integrated dissipation rates to determine their relative importance to observed diapycnal mixing. Although both internal tide and wind sources are used in this comparison, only correlation between microstructure observations and internal tide sources proves robust, dominating over wind in all but one dataset. By comparing observed total dissipation $D$ to the anticipated power input from each source individually, regional variability of the relative importance of each source within the different sets of microstructure observations is apparent (Fig. 4). For each microstructure observation presented in Fig. 4, the power from each source was obtained in a surrounding $1^{\circ} \times 1^{\circ}$ box. For all microstructure observations except EXITS and MIXET (where project-averaged observations are plotted), estimates of $D$ from individual microstructure profiles are plotted to display the variability within each dataset. The 1:1 ratio in Fig. 4 is similar to that in Fig. 3, but only includes a single source (internal tides or winds).

Both among and within many datasets, there is a correlation between internal tide power input and local dissipation. Several individual observations in the panel displaying the tidal input (Fig. 4a) follow the slope of the 1:1 ratio line [BBTRE (rough) and the North Atlantic Tracer Release Experiment (NATRE) with the lowest mean square error of the 1:1 fit]. In BBTRE (rough), observed $D$ fall on the 1:1 ratio over two orders of magnitude (from $10^{-4}$ to $10^{-2} \mathrm{~W} \mathrm{~m}^{-2}$ ), consistent with a balance 

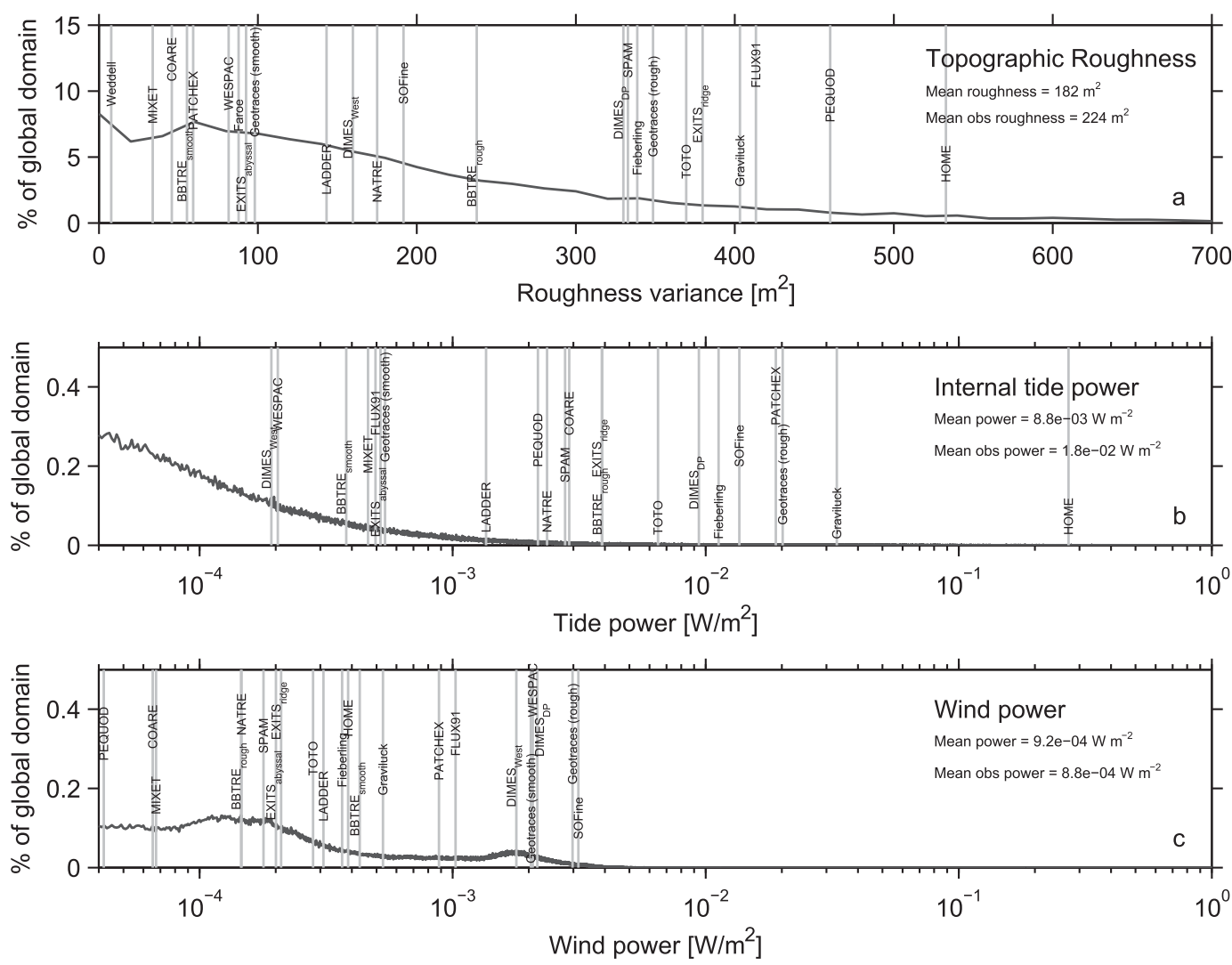

FIG. 5. Histograms of the (a) distribution of topographic roughness variance from global bathymetry and the total power input to the internal wave field from the (b) internal tide and (c) winds (annual mean), plotted as a percentage of the total global domain. The global distribution of roughness variance, from Whalen et al. (2012), is plotted in 20-m bins. Total tidal and wind power histograms [(b) and (c)] have bins ranging from $4 \times 10^{-5}$ to $10\left(\mathrm{~W} \mathrm{~m}^{-2}\right)$ with a bin size of $10^{-6}$. The topography and power input from the compiled microstructure observations are noted in (a) as the average roughness value from all profile stations and in (b) and (c) as the average power within a $1^{\circ} \times 1^{\circ}$ box around each of the profile stations. Global-mean values of roughness and power input and mean values where only microstructure measurements were made are noted.

between tidally generated sources and local dissipation over the full range of tidal power input. DIMES-West, a region dominated by wind power input, is at the lowest end of tidal generation and is mostly above the 1:1 line.

A correlation between wind power input into nearinertial waves and dissipation is not as clear (Fig. 4b). Though SOFine, GEOTRACES (rough and smooth), DIMES-West, and DIMES-DP have strong wind inputs, only in DIMES-West and GEOTRACES (smooth) does wind power input exceed tidal. GOLD was run during a year not associated with any of the observations, and nearinertial wind forcing is intermittent (D'Asaro 1985), so a good correlation between the observed dissipation rates and annual-mean wind power input is not expected. In addition, microstructure observations are typically not collected during strong wind forcing due to ship and sampling constraints. Many of the observed total dissipation rates lie above the 1:1 ratio (Fig. 4b), indicating that dissipation is driven by tidal forcing, lee wave, or energy fluxes from the neighboring ocean rather than wind forcing.

Because total dissipation varies regionally, the next step is determining how well this compilation of microstructure observations describes mixing variability in the ocean.

\section{f. Robustness of the global microstructure dataset: How well have we sampled the ocean?}

Common concerns regarding microstructure averages of mixing are (i) the extreme sparseness of the data and (ii) the observed variability spanning four orders of magnitude. Here, we follow Huussen et al. (2012) to assess how well sampled the microstructure data are, by comparing the locations of existing data to global distributions of power input into internal waves from wind and tides (Fig. 5). We also consider the global map of topographic roughness, which has been repeatedly linked to enhanced turbulent mixing somewhat independently 
of the details of internal wave generation or destruction (e.g., Decloedt and Luther 2010).

Roughness is defined as the variance of bathymetric height obtained from 1-min resolution bathymetry obtained from ship depth soundings (version 14.1; Smith and Sandwell 1997), calculated in 30-km square regions (Whalen et al. 2012). Multibeam bathymetry is required to characterize the scales of topography relevant to internal tide-driven mixing (Kunze and Llewellyn-Smith 2004; Polzin 2004b), and 30-km square regions are at an appropriate scale to resolve internal tide generation (St. Laurent and Garrett 2002). Topographic roughness variance is used here as a proxy for the types of topography that characterize the locations of the microstructure datasets (Fig. 5a). Microstructure profiles span most of the dynamic range of topographic roughness variability and bathymetric types including ridges and rough and smooth topography.

Observations over abrupt isolated ridgelike features include the Hawaiian Ridge (HOME), the crest of the Mid-Atlantic Ridge (GRAVILUCK), Drake Passage (DIMES-DP), Fieberling Guyot, and a ridge in the South Pacific [EXITS (ridge)]. Typically, ridges have been found to be strong internal tide generators with little local dissipation (Althaus et al. 2003), as observed at the Hawaiian Ridge (HOME; Fig. 3; Klymak et al. 2006).

Regions of rough topography are also well covered by microstructure observations. BBTRE data were collected on the west side of the Mid-Atlantic Ridge (as well as over the smooth region west of the Mid-Atlantic Ridge) and shows enhanced bottom dissipation rates over the rough topography (Polzin et al. 1997). GEOTRACES (rough) data come to the southern extent of the Mid-Atlantic Ridge (and the smooth region east of the ridge), with similarly enhanced near-bottom dissipation rates over the rough topography of the ridge, decreasing to the east. Observations over a fast-spreading ridge of the East Pacific Rise (LADDER) show that topography results in enhanced mixing due to both tidal and subinertial modulations (Thurnherr and St. Laurent 2011). SOFine profiles are from the Kerguelen Plateau in the Southern Ocean, where lee-wave generation by the geostrophic flow is expected to be a significant influence (Waterman et al. 2013a), as it is in Drake Passage (DIMES-DP; Sheen et al. 2013). EXITS (abyssal) observations were collected in an abyssal region away from a ridge, where internal waves generated at the Hawaiian Ridge disappear from satellite altimetry (Johnston et al. 2003).

Regions of smooth topography are associated with weak mixing (Toole et al. 1994; Kunze and Sanford 1996). The NATRE study in the eastern North Atlantic is characterized by minimal wind work but includes some dissipation of internal waves generated elsewhere (Polzin and Ferrari 2004; Polzin and Lvov 2011). DIMES-West is from the Pacific side of Drake Passage where winds are strong but steady, and therefore not resonant to the generation of inertial oscillations, and dissipation rates are weak (Ledwell et al. 2011). Unpublished observations from the equatorial Pacific at $156^{\circ} \mathrm{E}$ (MIXET) provide the first full-depth microstructure observations in a region of relatively smooth topography at the equator.

Globally, average internal tide power input is estimated to be $0.9 \times 10^{-2} \mathrm{~W} \mathrm{~m}^{-2}$, while the average internal tide power input from locations where we have microstructure observations is $1.8 \times 10^{-2} \mathrm{~W} \mathrm{~m}^{-2}$, a factor of 2 bias (Fig. 5b). Microstructure observations span a range of tidal power inputs to the internal wave field and are relatively well distributed, with a slight bias toward higher tidal power inputs. HOME and GRAVILUCK have the highest internal tide power input, while and DIMES-West the lowest (Fig. 5b).

The global-averaged wind power input into low-mode near-inertial waves is estimated to be $9.2 \times 10^{-4} \mathrm{~W} \mathrm{~m}^{-2}$ while that from locations where there are microstructure observations is $8.8 \times 10^{-4} \mathrm{~W} \mathrm{~m}^{-2}$ (Fig. $5 \mathrm{c}$ ). But as microstructure observations in regions where wind power input is greater than tidal WESPAC power input is sparse (section $3 \mathrm{e}$ ), the compiled dataset has only partially sampled the full range of the global distribution of power input from the winds (Fig. 5c).

Globally, tidal power input to the internal wave field is the dominant internal wave source considered here; wind forcing is roughly one-third of the total power input. As our sampling of the global distribution of wind power input is not expected to result in a significant bias, average $K$ and $\epsilon$ values estimated in Table 2 are not expected to be biased, spanning the range of power sources and bottom roughness values (uncertain by a factor of 2).

Not included is the power input due to lee waves, as it has been relatively undersampled but, globally, is a weaker power source than both winds and tides at 0.2 TW (Nikurashin and Ferrari 2011; Melet et al. 2014). We do, however, include several Southern Ocean sites in our compilation where we expect this power source may be significant, as well as observations from other locations where lee waves are expected to be a potential source of internal wave generation.

\section{g. Depth structure of $\epsilon$ and $K$}

The complete set of compiled 150-m-binned vertical profiles of dissipation rate $\epsilon$ and diffusivity $K$ is plotted as project averages (Fig. 6). Both dissipation rate and diffusivity range over four orders of magnitude.

Finescale-inferred diffusivity profiles (black lines in Fig. 6b) show latitudinal dependence (Kunze et al. 2006). 

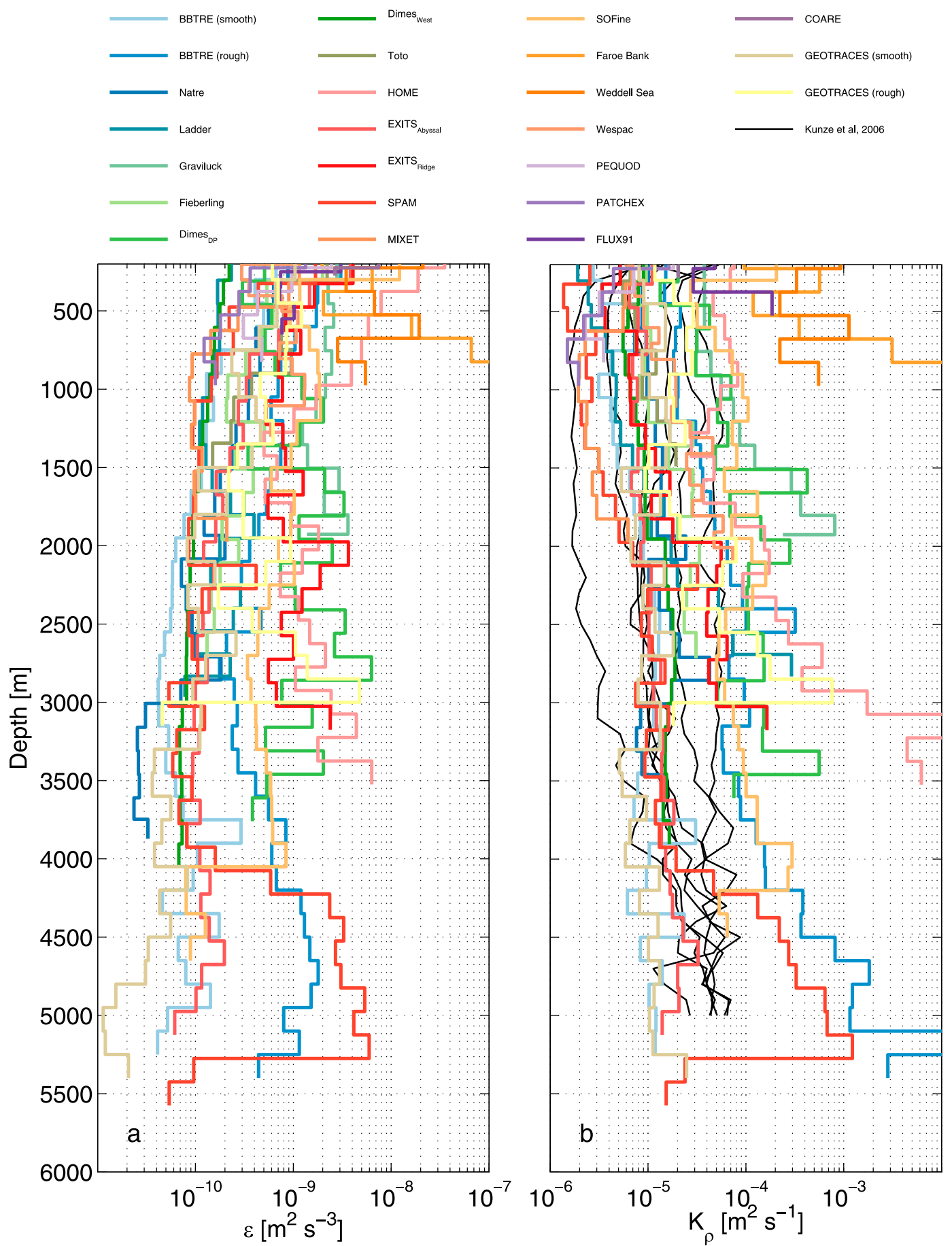

FIG. 6. All compiled vertical profiles of (a) dissipation rate $\left(\mathrm{m}^{2} \mathrm{~s}^{-3}\right)$ and (b) diffusivity $\left(\mathrm{m}^{2} \mathrm{~s}^{-1}\right)$ in 150 -m vertical bins. BBTRE and GEOTRACES data are grouped by those profiles collected over smooth and rough topography. Profiles from Fig. 17a of Kunze et al. (2006) are included in (b) (black lines), showing the latitudinal dependence of $K$ as calculated from application of a finescale parameterization.

They span a similar range as the microstructure profiles but fall short in locations where turbulence generation processes other than the internal wave-wave interaction cascade dominate such as hydraulic overflows (SPAM,
Färoe Bank Channel, Weddell Sea, and GRAVILUCK), internal tide (HOME and DIMES-DP), and lee-wave generation (SOFine) sites, locations of near-critical reflection and on the equator (MIXET). 


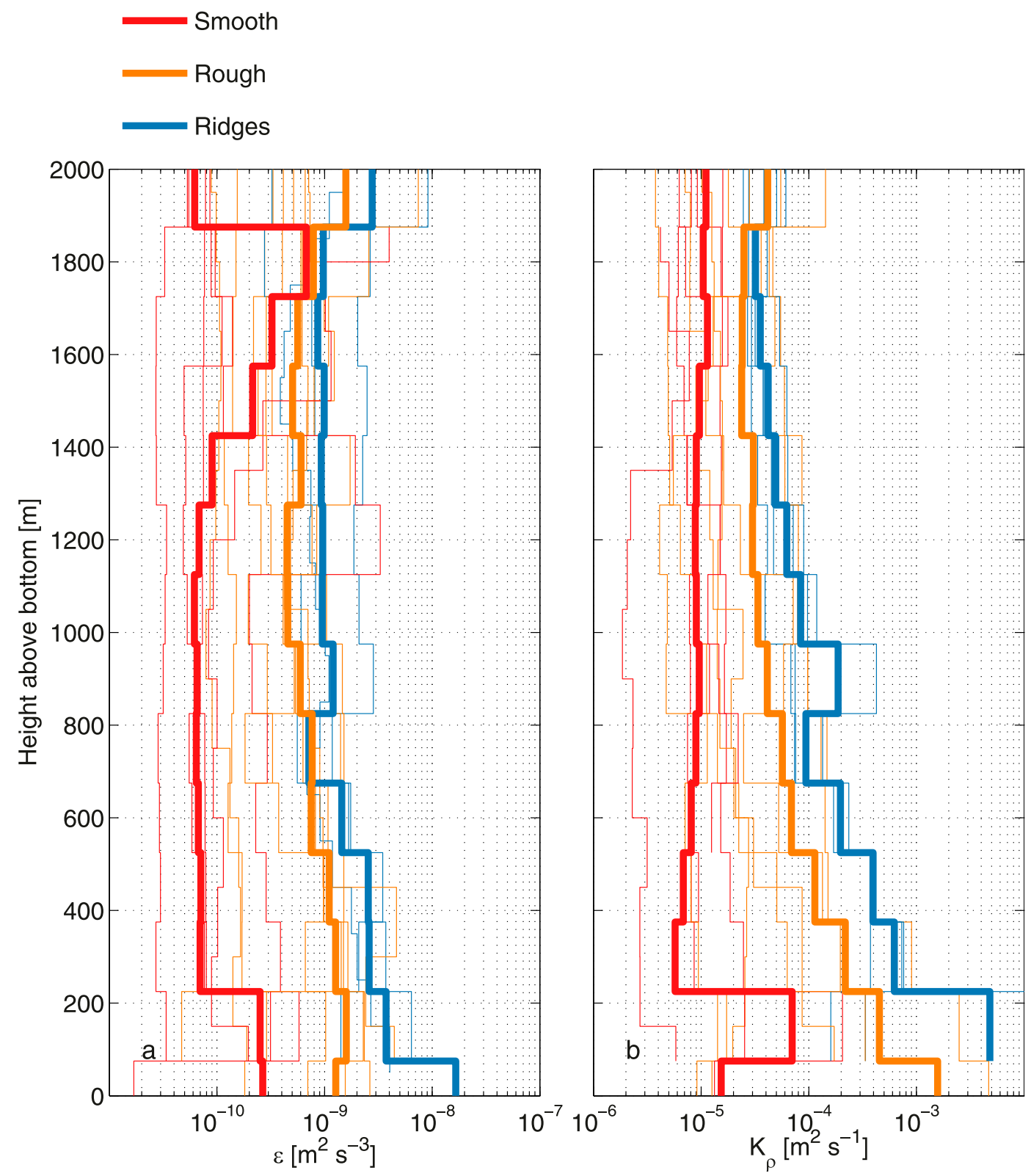

FIG. 7. Vertical profiles of (a) dissipation rate $\left(\mathrm{m}^{2} \mathrm{~s}^{-3}\right)$ and (b) diffusivity $\left(\mathrm{m}^{2} \mathrm{~s}^{-1}\right)$ plotted as a function of height above bottom from microstructure profiles with observations deeper than at least $2000 \mathrm{~m}$ above the bottom. Profiles are grouped into three types based on topography: smooth (red), rough (orange), and ridges (blue). Average profiles of $\epsilon$ and $K$ from each of the three groupings are the thicker red, orange, and blue lines. BBTRE and GEOTRACES data are grouped by those profiles collected over smooth and rough topography.

Binned by topographic regime (Fig. 7; section 3c), vertical profiles of dissipation rate $\epsilon$ and diffusivity $K$ are enhanced by two orders of magnitude in the bottom $1500 \mathrm{~m}$ over abrupt ridges and rough topography compared to smooth topography, as also found by Polzin et al. (1997), Kunze et al. (2006), and Decloedt and Luther (2010). Shallower than $1500 \mathrm{~m}$ above bottom (mab), diffusivity profiles converge more than dissipation rate due to varying $N^{2}$ above 1500 mab.

\section{Discussion and conclusions}

We have compiled a global dataset of estimates of turbulent dissipation rate $\epsilon$ and diffusivity $K$ from direct microstructure measurements of microscale shear and indirect estimates inferred from application of a finescale parameterization and density overturns. The observed depth-averaged diapycnal diffusivity based on the microstructure observations is 
$O\left(10^{-4}\right) \mathrm{m}^{2} \mathrm{~s}^{-1}$ below 1000-m depth and $O\left(10^{-5}\right) \mathrm{m}^{2} \mathrm{~s}^{-1}$ above (Table 2).

Our average diffusivities are similar to those presented in St. Laurent and Simmons (2006) based on a subset of the microstructure data used here. Below 1000 -m depth, our global-averaged abyssal diffusivity is of the same order of magnitude as that based on a vertical advective-diffusive balance (Munk 1966; Munk and Wunsch 1998) to maintain abyssal stratification given bottom-water formation rates. Regional hydrographic inverse models infer diapycnal diffusivities of similar magnitude to ours and also find bottom intensification [Naveira Garabato et al. (2003) and Macdonald et al. (2009) for the Southern and Pacific Oceans, respectively]. The inverse model from Lumpkin and Speer (2007) was designed to minimize diapycnal mixing and is the most appropriate hydrographic inverse model for our global comparisons. Their global-averaged $K$ between $32^{\circ} \mathrm{S}$ and $48^{\circ} \mathrm{N}$ is $O\left(10^{-4}\right) \mathrm{m}^{2} \mathrm{~s}^{-1}$ in the abyss and $O\left(10^{-5}\right) \mathrm{m}^{2} \mathrm{~s}^{-1}$ in the pycnocline. The inverse model diffusivities from Ganachaud and Wunsch (2000) are an order of magnitude higher than those inferred here.

Though sparse, the microstructure observations in our compilation span a broad range of both energetic and quiet locations based on anticipated tidal power inputs (Fig. 5), resulting in estimates that should not be unreasonably biased. Underlying these global averages is large variability, both laterally and vertically. Lateral variations correlate with the expected internal wave generation by tides spanning over four orders of magnitude (Figs. 1, 2, 3, 6). Over rough or abrupt ridge topography, the turbulent diffusivity is bottom enhanced compared to smooth topography (Fig. 7).

Given that internal waves are thought to produce most of the turbulence in the ocean interior, a major goal of this analysis is to compare microstructure-based turbulent dissipation rates with the global magnitude and patterns of the expected power inputs from winds and tides. Even neglecting power input from dense overflows and lee waves, and with a factor of 2 uncertainty, most depth-integrated dissipation rates are either equal to or less than estimated tidal and wind power (Fig. 3). For example, over rough topography [e.g. BBTRE (rough)], almost all the estimated power going into internal tide generation appears to be dissipated locally (Fig. 3). In contrast, at abrupt ridges (e.g., HOME), well over half of the generated internal tide energy radiates away to dissipate elsewhere. In situ and altimetric measurements show that the majority of this energy goes into low-mode internal waves that may propagate thousands of kilometers (Zhao and Alford 2009; Dushaw et al. 2011).

Total power input to the internal wave field from tides and winds is $1.8 \mathrm{TW}$, as estimated from GOLD. Given that the preponderance of datasets has less local dissipation than generation, a natural conclusion is that this excess power is not dissipating in the basin interior. Comparing the power input to the observed total dissipation (Fig. 3) indicates that approximately $69 \%$ of total power input is dissipated within the basin interior. If we were to consider the data in Fig. 3 as representative, then roughly $0.6 \mathrm{TW}$ ( $31 \%$ of the total power input) is available for dissipation on the continental slope (see, e.g., Nash et al. 2004, 2007; Martini et al. 2011) or in shelf slope canyons (see, e.g., Carter and Gregg 2002; Kunze et al. 2012).

All current parameterizations for diapycnal diffusivity consider only local internal wave-driven mixing (Melet et al. 2013). New parameterizations are being developed for global ocean models to take into account some, but not all, of the observed variability in diapycnal diffusivity (Polzin 2009; Jochum et al. 2013; Melet et al. 2013; Olbers and Eden 2013). Continued efforts are necessary to accurately forecast momentum and tracer distributions resulting from the combination of mixing from both locally and remotely generated internal waves for both the present and future climate.

Acknowledgments. This research was funded by the Climate Process Team (CPT) on internal wave-driven mixing through NSF Grant OCE-0968721. The authors are grateful to members of the internal wave-driven mixing CPT for useful discussions and suggestions, Jim Moum for providing data from FLUX91 and COARE experiments, and to Andreas M. Thurnherr, who provided data as well as helpful manuscript suggestions. Comments from two anonymous reviewers helped to substantially improve this manuscript. GSC acknowledges support from NSF Grants OCE-0825266 (EXITS), OCE-1029483 (SPAM), and OCE-1029722 (MIXET). LDT and CBW acknowledge support from NSF Grant OCE-0927650. SW and ACNG acknowledge support from NERC Grant NE/G001510/1 (SOFine).

\section{REFERENCES}

Alford, M. H., 2001: Internal swell generation: The spatial distribution of energy flux from the wind to mixed layer near-inertial motions. J. Phys. Oceanogr., 31, 2359-2368, doi:10.1175/ 1520-0485(2001)031<2359:ISGTSD>2.0.CO;2.

, 2003: Redistribution of energy available for ocean mixing by long-range propagation of internal waves. Nature, 423, 159162, doi:10.1038/nature01628.

, 2010: Sustained, full-water-column observations of internal waves and mixing near Mendocino Escarpment. J. Phys. Oceanogr., 40, 2643-2660, doi:10.1175/2010JPO4502.1.

, M. C. Gregg, and M. Merrifield, 2006: Structure, propagation, and mixing of energetic baroclinic tides in Mamala Bay, Oahu, Hawaii. J. Phys. Oceanogr., 36, 997-1018, doi:10.1175/ JPO2877.1. 
- and Coauthors, 2011: Energy flux and dissipation in Luzon Strait: Two tales of two ridges. J. Phys. Oceanogr., 41, 22112222, doi:10.1175/JPO-D-11-073.1.

—, M. F. Cronin, and J. M. Klymak, 2012: Annual cycle and depth penetration of wind-generated near-inertial internal waves at Ocean Station Papa in the northeast Pacific. J. Phys. Oceanogr., 42, 889-909, doi:10.1175/JPO-D-11-092.1.

Althaus, A., E. Kunze, and T. Sanford, 2003: Internal tide radiation from Mendocino Escarpment. J. Phys. Oceanogr., 33, 1510-1527, doi:10.1175/1520-0485(2003)033<1510:ITRFME >2.0.CO;2.

Baines, P. G., 1982: On internal tide generation models. Deep-Sea Res. I, 29, 307-338, doi:10.1016/0198-0149(82)90098-X.

Bell, T. H., 1975: Topographically generated internal waves in the open ocean. J. Geophys. Res., 80, 320-327, doi:10.1029/ JC080i003p00320.

Bray, N., and N. P. Fofonoff, 1981: Available potential-energy for MODE eddies. J. Phys. Oceanogr., 11, 30-47, doi:10.1175/ 1520-0485(1981)011<0030:APEFME > 2.0.CO;2.

Carter, G., and M. Gregg, 2002: Intense, variable mixing near the head of Monterey Submarine Canyon. J. Phys. Oceanogr., 32, 3145-3165, doi:10.1175/1520-0485(2002)032<3145: IVMNTH $>2.0 . \mathrm{CO} ; 2$.

Crawford, W. R., 1986: A comparison of length scales and decay times of turbulence in stably stratified flows. J. Phys. Oceanogr., 16, 1847-1854, doi:10.1175/1520-0485(1986)016<1847: ACOLSA $>2.0 . \mathrm{CO} ; 2$.

D'Asaro, E. A., 1985: The energy flux from the wind to nearinertial motions in the surface mixed layer. J. Phys. Oceanogr., 15, 1043-1059, doi:10.1175/1520-0485(1985)015<1043: TEFFTW $>2.0 . \mathrm{CO} ; 2$.

__ 1995: Upper-ocean inertial currents forced by a strong storm. III: Interaction of inertial currents and mesoscale eddies. J. Phys. Oceanogr., 25, 2953-2958, doi:10.1175/ 1520-0485(1995)025<2953:UOICFB > 2.0.CO;2.

_ , and M. D. Morehead, 1991: Internal waves and velocity fine structure in the Arctic Ocean. J. Geophys. Res., 96, 1272512738, doi:10.1029/91JC01071.

Decloedt, T., and D. S. Luther, 2010: On a simple empirical parameterization of topography-catalyzed diapycnal mixing in the abyssal ocean. J. Phys. Oceanogr., 40, 487-508, doi:10.1175/ 2009JPO4275.1.

Dillon, T. M., 1982: Vertical overturns: A comparison of Thorpe and Ozmidov length scales. J. Geophys. Res., 87, 9601-9613, doi:10.1029/JC087iC12p09601.

Dohan, K., and R. E. Davis, 2011: Mixing in the transition layer during two storm events. J. Phys. Oceanogr., 41, 42-66, doi:10.1175/2010JPO4253.1.

Dushaw, B. D., P. F. Worcester, and M. A. Dzieciuch, 2011: On the predictability of mode-1 internal tides. Deep-Sea Res. I, 58, 677-698, doi:10.1016/j.dsr.2011.04.002.

Egbert, G. D., and R. D. Ray, 2000: Significant dissipation of tidal energy in the deep ocean inferred from satellite altimeter data. Nature, 405, 775-778, doi:10.1038/35015531.

- and - 2001: Estimates of $\mathrm{M}_{2}$ tidal energy dissipation from TOPEX/Poseidon altimeter data. J. Geophys. Res., 106, 22 475-22 502, doi:10.1029/2000JC000699.

Fer, I., G. Voet, K. S. Seim, B. Rudels, and K. Latarius, 2010: Intense mixing of the Faroe Bank Channel overflow. Geophys. Res. Lett., 37, L02604, doi:10.1029/2009GL041924.

Ferron, B., H. Mercier, K. Speer, A. Gargett, and K. L. Polzin, 1998: Mixing in the Romanche Fracture Zone. J. Phys. Oceanogr., 28, 1929-1945, doi:10.1175/1520-0485(1998)028<1929: MITRFZ>2.0.CO;2.
Furuichi, N., T. Hibiya, and Y. Niwa, 2008: Model-predicted distribution of wind-induced internal wave energy in the world's oceans. J. Geophys. Res., 113, C09034, doi:10.1029/ 2008JC004768.

Ganachaud, A., and C. Wunsch, 2000: Improved estimates of global ocean circulation, heat transport and mixing from hydrographic data. Nature, 408, 453-457, doi:10.1038/ 35044048.

Garrett, C., and E. Kunze, 2007: Internal tide generation in the deep ocean. Annu. Rev. Fluid Mech., 39, 57-87, doi:10.1146/ annurev.fluid.39.050905.110227.

Gouretski, V. V., and K. P. Koltermann, 2004: WOCE global hydrographic climatology: A technical report. Bundesamt Seeschiffahrt Hydrogr., 35, 1-52.

Gregg, M. C., 1989: Scaling turbulent dissipation in the thermocline. J. Geophys. Res., 94, 9686-9698, doi:10.1029/ JC094iC07p09686.

- 1998: Estimation and geography of diapycnal mixing in the stratified ocean. Physical Processes in Lakes and Oceans, J. Imberger, Ed., Amer. Geophys. Union, 305-338.

, 1999: Uncertainties and limitations in measuring $\epsilon$ and $\chi$. J. Atmos. Oceanic Technol., 16, 1483-1490, doi:10.1175/ 1520-0426(1999)016<1483:UALIMA > 2.0.CO;2.

— , and T. B. Sanford, 1988: The dependence of turbulent dissipation on stratification in a diffusively stable thermocline. J. Geophys. Res., 93, 12381-12392, doi:10.1029/ JC093iC10p12381.

, and E. Kunze, 1991: Shear and strain in Santa Monica basin. J. Geophys. Res., 96, 16 709-16719, doi:10.1029/91JC01385.

_ E. E. A. D'Asaro, T. J. Shay, and N. Larson, 1986: Observations of persistent mixing and near-inertial internal waves. J. Phys. Oceanogr., 16, 856-885, doi:10.1175/1520-0485(1986)016<0856: OOPMAN $>2.0 . \mathrm{CO} ; 2$.

- T. B. Sanford, and D. P. Winkel, 2003: Reduced mixing from the breaking of internal waves in equatorial waters. Nature, 422, 513-515, doi:10.1038/nature01507.

Hebert, D., and J. N. Moum, 1994: Decay of a near-inertial wave. J. Phys. Oceanogr., 24, 2334-2351, doi:10.1175/ 1520-0485(1994)024<2334:DOANIW>2.0.CO;2.

Heywood, K. J., A. C. Naveira Garabato, and P. D. Stevens, 2002: High mixing rates in the abyssal Southern Ocean. Nature, 415, 1011-1014, doi:10.1038/4151011a.

Hogan, T. F., and T. E. Rosmond, 1991: The description of the Navy Operational Global Atmospheric Prediction System's spectral forecast model. Mon. Wea. Rev., 119, 1786-1815, doi:10.1175/1520-0493(1991)119<1786:TDOTNO > 2.0.CO;2.

Holte, J., and L. Talley, 2009: A new algorithm for finding mixed layer depths with applications to Argo data and subantarctic mode water formation. J. Atmos. Oceanic Technol., 26, 19201939, doi:10.1175/2009JTECHO543.1.

Hooper, J. A., 2011: Dissipation processes in the tongue of the ocean. M.S. thesis, Department of Earth, Ocean, and Atmospheric Sciences, Florida State University, 38 pp.

Huussen, T. N., A. C. Naveira-Garabato, H. L. Bryden, and E. L. McDonagh, 2012: Is the deep Indian Ocean MOC sustained by breaking internal waves? J. Geophys. Res., 117, C08024, doi:10.1029/2012JC008236.

Jiang, J., Y. Y. Lu, and W. Perrie, 2005: Estimating the energy flux from the wind to ocean inertial motions: The sensitivity to surface wind fields. Geophys. Res. Lett., 32, L15610, doi:10.1029/ 2005 GL023289.

Jochum, M., B. P. Briegleb, G. Danabasoglu, W. G. Large, N. J. Norton, S. R. Jayne, M. H. Alford, and F. O. Bryan, 2013: The 
impact of oceanic near-inertial waves on climate. J. Climate, 26, 2833-2844, doi:10.1175/JCLI-D-12-00181.1.

Johnston, T. M. S., M. A. Merrifield, and P. E. Holloway, 2003: Internal tide scattering at the Line Islands Ridge. J. Geophys. Res., 108, 3365, doi:10.1029/2003JC001844.

Kelly, S. M., J. D. Nash, and E. Kunze, 2010: Internal-tide energy over topography. J. Geophys. Res., 115, C06014, doi:10.1029/ 2009JC005618.

Klymak, J. M., and Coauthors, 2006: An estimate of tidal energy lost to turbulence at the Hawaiian Ridge. J. Phys. Oceanogr., 36, 1148-1164, doi:10.1175/JPO2885.1.

—, R. Pinkel, and L. Rainville, 2008: Direct breaking of the internal tide near topography: Kaena Ridge, Hawaii. J. Phys. Oceanogr., 38, 380-399, doi:10.1175/2007JPO3728.1.

Kunze, E., and T. B. Sanford, 1996: Abyssal mixing: Where it is not. J. Phys. Oceanogr., 26, 2286-2296, doi:10.1175/ 1520-0485(1996)026<2286:AMWIIN>2.0.CO;2.

- and J. Toole, 1997: Tidally driven vorticity, diurnal shear, and turbulence atop Fieberling Seamount. J. Phys. Oceanogr., 27, 2663-2693, doi:10.1175/1520-0485(1997)027<2663: TDVDSA $>2.0 . \mathrm{CO} ; 2$.

— pography in turbulent mixing of the global ocean. Oceanography, 17, 55-64, doi:10.5670/oceanog.2004.67.

—, E. Firing, J. M. Hummon, T. K. Chereskin, and A. M. Thurnherr, 2006: Global abyssal mixing inferred from lowered ADCP shear and CTD strain profiles. J. Phys. Oceanogr., 36, 1553-1576, doi:10.1175/JPO2926.1.

—, C. MacKay, E. E. McPhee-Shaw, K. Morrice, J. B. Girton, and S. R. Terker, 2012: Turbulent mixing and exchange with interior waters on sloping boundaries. J. Phys. Oceanogr., 42, 910-927, doi:10.1175/JPO-D-11-075.1.

Kurapov, A. L., G. Egbert, J. S. Allen, R. N. Miller, S. Y. Erofeeva, and P. M. Kosro, 2003: The $M_{2}$ internal tide off Oregon: Inferences from data assimilation. J. Phys. Oceanogr., 33, 17331757, doi:10.1175/2397.1.

Large, W., and G. B. Crawford, 1995: Observations and simulations of upper-ocean response to wind events during the Ocean Storms Experiment. J. Phys. Oceanogr., 25, 2831-2852, doi:10.1175/1520-0485(1995)025<2831:OASOUO>2.0.CO;2.

Ledwell, J. R., E. Montgomery, K. L. Polzin, L. C. St. Laurent, R. Schmitt, and J. Toole, 2000: Evidence for enhanced mixing over rough topography in the abyssal ocean. Nature, 403, 179182, doi:10.1038/35003164.

_ L. C. St. Laurent, J. Girton, and J. M. Toole, 2011: Diapycnal mixing in the Antarctic Circumpolar Current. J. Phys. Oceanogr., 41, 241-246, doi:10.1175/2010JPO4557.1.

Lee, C. M., E. Kunze, T. B. Sanford, J. D. Nash, M. A. Merrifield, and P. E. Holloway, 2006: Internal tides and turbulence along the 3000-m isobath of the Hawaiian Ridge. J. Phys. Oceanogr., 36, 1165-1183, doi:10.1175/JPO2886.1.

Legg, S., 2014: Scattering of low-mode internal waves at finite isolated topography. J. Phys. Oceanogr., 44, 359-383, doi:10.1175/JPO-D-12-0241.1.

Levine, M. D., C. A. Paulson, and J. H. Morison, 1987: Observations of internal gravity waves under the Arctic pack ice. J. Geophys. Res., 92, 779-782, doi:10.1029/JC092iC01p00779.

Lueck, R. G., 1988: Turbulent mixing at the Pacific Subtropical Front. J. Phys. Oceanogr., 18, 1761-1774, doi:10.1175/ 1520-0485(1988)018<1761:TMATPS >2.0.CO;2.

, and R. Reid, 1984: On the production and dissipation of mechanical energy in the ocean. J. Geophys. Res., 89, 34393445, doi:10.1029/JC089iC03p03439.
— , and T. R. Osborn, 1985: Turbulence measurements in a submarine canyon. Cont. Shelf Res., 4, 681-698, doi:10.1016/ 0278-4343(85)90036-6.

— and - 1986: The dissipation of kinetic energy in a warmcore ring. J. Geophys. Res., 91, 803-818, doi:10.1029/ JC091iC01p00803.

— W. R. Crawford, and T. R. Osborn, 1983: Turbulent dissipation over the continental slope off Vancouver Island. J. Phys. Oceanogr., 13, 1809-1818, doi:10.1175/1520-0485(1983)013<1809: TDOTCS $>2.0 . \mathrm{CO} ; 2$.

- D. Huang, D. Newman, and J. Box, 1997: Turbulence measurement with a moored instrument. J. Atmos. Oceanic Technol., 14, 143-161, doi:10.1175/1520-0426(1997)014<0143: TMWAMI $>2.0 . \mathrm{CO} ; 2$.

Lumpkin, R., and K. Speer, 2007: Global ocean meridional overturning. J. Phys. Oceanogr., 37, 2550-2562, doi:10.1175/ JPO3130.1.

Macdonald, A. M., S. Mecking, P. E. Robbins, J. M. Toole, G. C. Johnson, L. Talley, M. Cook, and S. E. Wijffels, 2009: The WOCE-era 3-D Pacific Ocean circulation and heat budget. Prog. Oceanogr., 82, 281-325, doi:10.1016/j.pocean.2009.08.002.

MacKinnon, J. A., M. H. Alford, R. Pinkel, J. M. Klymak, and Z. Zhao, 2013a: The latitudinal dependence of shear and mixing in the Pacific transiting the critical latitude for PSI. J. Phys. Oceanogr., 43, 3-16, doi:10.1175/JPO-D-11-0107.1.

_ L. C. St. Laurent, and A. C. Naveira Garabato, 2013b: Dianeutral transport processes in the ocean interior. Ocean Circulation and Climate a 21st Century Perspective, G. Siedler et al., Eds., Academic Press, 159-183.

Martini, K. I., M. H. Alford, E. Kunze, S. M. Kelly, and J. D. Nash, 2011: Observations of internal tides on the Oregon continental slope. J. Phys. Oceanogr., 41, 1772-1794, doi:10.1175/ 2011JPO4581.1.

Melet, A., R. Hallberg, S. Legg, and K. L. Polzin, 2013: Sensitivity of the ocean state to the vertical distribution of internal-tidedriven mixing. J. Phys. Oceanogr., 43, 602-615, doi:10.1175/ JPO-D-12-055.1.

,,,--- and M. Nikurashin, 2014: Sensitivity of the ocean state to lee wave-driven mixing. J. Phys. Oceanogr., 44, 900921, doi:10.1175/JPO-D-13-072.1.

Moum, J. N., 1996a: Efficiency of mixing in the main thermocline. J. Geophys. Res., 101, 12057-12 069, doi:10.1029/ 96JC00508.

- 1996b: Energy-containing scales of turbulence in the ocean thermocline. J. Geophys. Res., 101, 14 095-14109, doi:10.1029/ 96JC00507.

— , and T. R. Osborn, 1986: Mixing in the main thermocline. J. Phys. Oceanogr., 16, 1250-1259, doi:10.1175/1520-0485 (1986)016<1250:MITMT>2.0.CO;2.

— - , and W. R. Crawford, 1986: Pacific equatorial turbulence: Revisited. J. Phys. Oceanogr., 16, 1516-1522, doi:10.1175/1520-0485(1986)016<1516:PETR > 2.0.CO;2.

— D. R. Caldwell, J. D. Nash, and G. D. Gunderson, 2002: Observations of boundary mixing over the continental slope. J. Phys. Oceanogr., 32, 2113-2130, doi:10.1175/1520-0485 (2002)032<2113:OOBMOT>2.0.CO;2.

— R. C. Lien, A. Perlin, J. D. Nash, M. C. Gregg, and P. J. Wiles, 2009: Sea surface cooling at the equator by subsurface mixing in tropical instability waves. Nat. Geosci., 2, 761-765, doi:10.1038/ngeo657.

Müller, P., and D. J. Olbers, 1975: On the dynamics of internal waves in the deep ocean. J. Geophys. Res., 80, 3848-3860, doi:10.1029/JC080i027p03848. 
_ , and N. Xu, 1992: Scattering of oceanic internal gravity waves off random bottom topography. J. Phys. Oceanogr., 22, 474-488, doi:10.1175/1520-0485(1992)022<0474:SOOIGW>2.0.CO;2.

Munk, W. H., 1966: Abyssal recipes. Deep-Sea Res. Oceanogr. Abstr., 13, 707-730, doi:10.1016/0011-7471(66)90602-4.

_- 1981: Internal waves and small-scale processes. Evolution of Physical Oceanography: Scientific Surveys in Honor of Henry Stommel, B. A. Warren and C. Wunsch, Eds., MIT Press, 264 291.

— , and C. Wunsch, 1998: Abyssal recipes II: Energetics of tidal and wind mixing. Deep-Sea Res. I, 45, 1977-2010, doi:10.1016/ S0967-0637(98)00070-3.

Nash, J. D., E. Kunze, J. Toole, and R. Schmitt, 2004: Internal tide reflection and turbulent mixing on the continental slope. J. Phys. Oceanogr., 34, 1117-1134, doi:10.1175/ 1520-0485(2004)034<1117:ITRATM>2.0.CO;2.

—, M. H. Alford, E. Kunze, K. I. Martini, and S. Kelly, 2007: Hotspots of deep ocean mixing on the Oregon continental slope. Geophys. Res. Lett., 34, L01605, doi:10.1029/ 2006GL028170.

Nasmyth, P. W., 1970: Oceanic turbulence. Ph.D. thesis, University of British Columbia, 69 pp.

Naveira Garabato, A. C., D. P. Stevens, and K. J. Heywood, 2003: Water mass conversion, fluxes, and mixing in the Scotia Sea diagnosed by an inverse model. J. Phys. Oceanogr., 33, 2565-2587, doi:10.1175/1520-0485(2003)033<2565:WMCFAM>2.0.CO;2.

Nikurashin, M., and R. Ferrari, 2011: Global energy conversion rate from geostrophic flows into internal lee waves in the deep ocean. Geophys. Res. Lett., 38, L08610, doi:10.1029/ 2011 GL046576.

Nycander, J., 2005: Generation of internal waves in the deep ocean by tides. J. Geophys. Res., 110, C10028, doi:10.1029/ 2004JC002487.

Oakey, N. S., 1982: Determination of the rate of dissipation of turbulent energy from simultaneous temperature and velocity shear microstructure measurements. J. Phys. Oceanogr., 12, 256-271, doi:10.1175/1520-0485(1982)012<0256: DOTROD $>2.0 . \mathrm{CO} ; 2$.

Olbers, D., and C. Eden, 2013: A global model for the diapycnal diffusivity induced by internal gravity waves. J. Phys. Oceanogr., 43, 1759-1779, doi:10.1175/JPO-D-12-0207.1.

Osborn, T. R., 1978: Measurements of energy dissipation adjacent to an island. J. Geophys. Res., 83, 2939-2957, doi:10.1029/ JC083iC06p02939.

_ 1980: Estimates of the local rate of vertical diffusion from dissipation measurements. J. Phys. Oceanogr., 10, 83-89, doi:10.1175/1520-0485(1980)010<0083:EOTLRO>2.0.CO;2.

_ , and W. R. Crawford, 1980: An airfoil probe for measuring turbulent velocity fluctuations in water. Air-Sea Interaction: Instruments and Methods, F. Dobson, L. Hasse, and R. Davis, Eds., Plenum Press, 369-386.

Pinkel, R., 2005: Near-inertial wave propagation in the western Arctic. J. Phys. Oceanogr., 35, 645-665, doi:10.1175/JPO2715.1.

__, 2012: Velocity imprecision in finite-beamwidth shipboard Doppler sonar: A first-generation correction algorithm. J. Atmos. Oceanic Technol., 29, 1569-1580, doi:10.1175/ JTECH-D-12-00041.1.

Plueddemann, A. J., and J. T. Farrar, 2006: Observations and models of the energy flux from the wind to mixed-layer inertial currents. Deep-Sea Res. II, 53, 5-30, doi:10.1016/j.dsr2.2005.10.017.

Polzin, K. L., 2004a: A heuristic description of internal wave dynamics. J. Phys. Oceanogr., 34, 214-230, doi:10.1175/ 1520-0485(2004)034<0214:AHDOIW>2.0.CO;2.
- 2004b: Idealized solutions for the energy balance of the finescale internal wave field. J. Phys. Oceanogr., 34, 231-246, doi:10.1175/1520-0485(2004)034<0231:ISFTEB > 2.0.CO;2.

, 2009: An abyssal recipe. Ocean Modell., 30, 298-309, doi:10.1016/j.ocemod.2009.07.006.

— , and R. Ferrari, 2004: Isopycnal dispersion in NATRE. J. Phys. Oceanogr., 34, 247-257, doi:10.1175/1520-0485(2004)034<0247: IDIN $>2.0 . \mathrm{CO} ; 2$.

- , and Y. V. Lvov, 2011: Toward regional characterizations of the oceanic internal wavefield. Rev. Geophys., 49, RG4003, doi:10.1029/2010RG000329.

_ zations of turbulent dissipation. J. Phys. Oceanogr., 25, 306-328, doi:10.1175/1520-0485(1995)025<0306:FPOTD>2.0.CO;2.

_ N. S. Oakey, J. M. Toole, and R. W. Schmitt, 1996: Fine structure and microstructure characteristics across the northwest Atlantic Subtropical Front. J. Geophys. Res., 101, 1411114 121, doi:10.1029/96JC01020.

_ - J. M. Toole, J. R. Ledwell, and R. Schmitt, 1997: Spatial variability of turbulent mixing in the abyssal ocean. Science, 276, 93-96, doi:10.1126/science.276.5309.93.

Rimac, A., J. S. von Storch, C. Eden, and H. Haak, 2013: The influence of high-resolution wind stress field on the power input to near-inertial motions in the ocean. Geophys. Res. Lett., 40, 4882-4886, doi:10.1002/grl.50929.

Rosmond, T. E., 1992: The design and testing of the navy operational global atmospheric prediction system. Wea. Forecasting, 7, 262-272, doi:10.1175/1520-0434(1992)007<0262: TDATOT $>2.0 . \mathrm{CO} ; 2$.

Rudnick, D. L., and Coauthors, 2003: From tides to mixing along the Hawaiian Ridge. Science, 301, 355-357, doi:10.1126/ science. 1085837.

Sheen, K. L., and Coauthors, 2013: Rates and mechanisms of turbulent dissipation and mixing in the Southern Ocean: Results from the Diapycnal and Isopycnal Mixing Experiment in the Southern Ocean (DIMES). J. Geophys. Res., 118, 2774-2792, doi:10.1002/jgrc.20217.

Simmons, H. L., and M. H. Alford, 2012: Simulating the long-range swell of internal waves generated by ocean storms. Oceanogr., 25, 30-41, doi:10.5670/oceanog.2012.39.

_ R. W. Hallberg, and B. K. Arbic, 2004a: Internal wave generation in a global baroclinic tide model. Deep-Sea Res. II, 51, 3043-3068, doi:10.1016/j.dsr2.2004.09.015.

_ S. R. Jayne, L. C. St. Laurent, and A. J. Weaver, 2004b: Tidally driven mixing in a numerical model of the ocean general circulation. Ocean Modell., 6, 245-263, doi:10.1016/ S1463-5003(03)00011-8.

Sjöberg, B., and A. Stigebrandt, 1992: Computations of the geographical distribution of the energy flux to mixing processes via internal tides and the associated vertical circulation in the ocean. Deep-Sea Res. I, 39, 269-291, doi:10.1016/ 0198-0149(92)90109-7.

Skyllingstad, E., W. Smith, J. N. Moum, and H. Wijesekera, 1999: Upper-ocean turbulence during a westerly wind burst: A comparison of large-eddy simulation results and microstructure measurements. J. Phys. Oceanogr., 29, 5-28, doi:10.1175/ 1520-0485(1999)029<0005:UOTDAW >2.0.CO;2.

Smith, W. H. F., and D. T. Sandwell, 1997: Global sea floor topography from satellite altimetry and ship depth soundings. Science, 277, 1956-1962, doi:10.1126/science.277.5334.1956.

Smyth, W., D. Hebert, and J. N. Moum, 1996a: Local ocean response to a multiphase westerly wind burst: 1 . Dynamic response. J. Geophys. Res., 101, 22 495-22 512, doi:10.1029/96JC02005. 
$[,-$, and $-1996 \mathrm{~b}$ : Local ocean response to a multiphase westerly wind burst: 2 . Thermal and freshwater responses. J. Geophys. Res., 101, 22 513-22 533, doi:10.1029/96JC02006.

—_, P. Zavialov, and J. N. Moum, 1997: Decay of turbulence in the upper ocean following sudden isolation from surface forcing. J. Phys. Oceanogr., 27, 810-822, doi:10.1175/ 1520-0485(1997)027<0810:DOTITU>2.0.CO;2.

St. Laurent, L. C., and R. W. Schmitt, 1999: The contribution of salt fingers to vertical mixing in the North Atlantic Tracer Release Experiment. J. Phys. Oceanogr., 29, 1404-1424, doi:10.1175/ 1520-0485(1999)029<1404:TCOSFT >2.0.CO;2.

— , and C. Garrett, 2002: The role of internal tides in mixing the deep ocean. J. Phys. Oceanogr., 32, 2882-2899, doi:10.1175/ 1520-0485(2002)032<2882:TROITI >2.0.CO;2.

— , and J. D. Nash, 2004: An examination of the radiative and dissipative properties of deep ocean internal tides. Deep-Sea Res. II, 51, 3029-3042, doi:10.1016/j.dsr2.2004.09.008.

— mixing in the ocean interior. J. Climate, 19, 4877-4890, doi:10.1175/JCLI3887.1.

— , and A. M. Thurnherr, 2007: Intense mixing of lower thermocline water on the crest of the Mid-Atlantic Ridge. Nature, 448, 680-683, doi:10.1038/nature06043.

— J. M. Toole, and R. W. Schmitt, 2001: Buoyancy forcing by turbulence above rough topography in the abyssal Brazil Basin. J. Phys. Oceanogr., 31, 3476-3495, doi:10.1175/ 1520-0485(2001)031<3476:BFBTAR >2.0.CO;2.

— , S. Stringer, C. Garrett, and D. Perrault-Joncas, 2003: The generation of internal tides at abrupt topography. Deep-Sea Res. I, 50, 987-1003, doi:10.1016/S0967-0637(03)00096-7.

_- A. C. Naveira Garabato, J. R. Ledwell, A. M. Thurnherr, J. M. Toole, and A. J. Watson, 2012: Turbulence and diapycnal mixing in Drake Passage. J. Phys. Oceanogr., 42, 2143-2152, doi:10.1175/JPO-D-12-027.1.

Talley, L. D., 2013: Closure of the global overturning circulation through the Indian, Pacific, and Southern Oceans: Schematics and transports. Oceanography, 26, 80-97, doi:10.5670/ oceanog.2013.07.

Thorpe, S. A., 1977: Turbulence and mixing in a Scottish loch. Philos. Trans. Roy. Soc. London, 286A, 125-181, doi:10.1098/ rsta.1977.0112.

, 2007: An Introduction to Ocean Turbulence. Cambridge University Press, 240 pp.
Thurnherr, A. M., and L. C. St. Laurent, 2011: Turbulence and diapycnal mixing over the East Pacific Rise crest near $10^{\circ} \mathrm{N}$. Geophys. Res. Lett., 38, L15613, doi:10.1029/2011GL048207.

Toole, J. M., R. W. Schmitt, and K. L. Polzin, 1994: Estimates of diapycnal mixing in the abyssal ocean. Science, 264, 1120 1123, doi:10.1126/science.264.5162.1120.

,,,--- and E. Kunze, 1997: Near-boundary mixing above the flanks of a midlatitude seamount. J. Geophys. Res., 102, 947-959, doi:10.1029/96JC03160.

Wang, W., and R. X. Huang, 2004: Wind energy input to the surface waves. J. Phys. Oceanogr., 34, 1276-1280, doi:10.1175/ 1520-0485(2004)034<1276:WEITTS > 2.0.CO;2.

Watanabe, M., and T. Hibiya, 2002: Global estimates of the wind-induced energy flux to inertial motions in the surface mixed layer. Geophys. Res. Lett., 29 (8), doi:10.1029/ 2001GL014422.

Waterman, S., A. C. Naveira Garabato, and K. L. Polzin, 2013: Internal waves and turbulence in the Antarctic Circumpolar Current. J. Phys. Oceanogr., 43, 259-282, doi:10.1175/ JPO-D-11-0194.1.

, K. L. Polzin, A. C. Naveira Garabato, K. L. Sheen, and A. Forryan, 2014: Suppression of internal wave breaking in the Antarctic Circumpolar Current near topography. J. Phys. Oceanogr., 44, 1466-1492, doi:10.1175/JPO-D-12-0154.1.

Wesson, J. C., and M. C. Gregg, 1994: Mixing at Camarinal Sill in the Strait of Gibraltar. J. Geophys. Res., 99, 9847-9878, doi:10.1029/94JC00256.

Whalen, C., L. D. Talley, and J. A. MacKinnon, 2012: Spatial and temporal variability of global ocean mixing inferred from Argo profiles. Geophys. Res. Lett., 39, L18612, doi:10.1029/ 2012GL053196.

Wijesekera, H., L. Padman, T. Dillon, M. Levine, C. Paulson, and R. Pinkel, 1993: The application of internal-wave dissipation models to a region of strong mixing. J. Phys. Oceanogr., 23, 269-286, doi:10.1175/1520-0485(1993)023<0269: TAOIWD $>2.0 . \mathrm{CO} ; 2$.

Wunsch, C., and R. Ferrari, 2004: Vertical mixing, energy and the general circulation of the oceans. Annu. Rev. Fluid Mech., 36, 281-314, doi:10.1146/annurev.fluid.36.050802.122121.

Zhao, Z., and M. H. Alford, 2009: New altimetric estimates of mode- $1 M_{2}$ internal tides in the central North Pacific Ocean. J. Phys. Oceanogr., 39, 1669-1684, doi:10.1175/ 2009JPO3922.1. 